\title{
Recent Progress on Advanced Blast Furnace Mathematical Models Based on Discrete Method
}

\author{
Tatsuro ARIYAMA, ${ }^{1{ }^{*}}$ Shungo NATSUI, ${ }^{2)}$ Tatsuya $\mathrm{KON}^{3)}$ Shigeru UEDA, ${ }^{3)}$ Shin $\mathrm{KIKUCH}^{3)}$ and \\ Hiroshi NOGAMI) \\ 1) Professor Emeritus, Tohoku University, Sendai, 980-8577 Japan. \\ 2) Division of Material Science and Engineering, Faculty of Engineering, Hokkaido University, Sapporo, 060-8628 Japan. \\ 3) Institute of Multidisciplinary Research for Advanced Materials, Tohoku University, Sendai, 980-8577 Japan.
}

(Received on February 3, 2014; accepted on April 2, 2014; originally published in Tetsu-to-Hagané,

Vol. 100, 2014, No. 2, pp. 198-210)

\begin{abstract}
From the backgrounds of the recent trends towards low reducing agent operation of large blast furnaces and application of diversified charging modes for various burdens, an advanced mathematical model of the blast furnace is required. Although conventional models based on the continuum model have been widely used, these models are not sufficient for the recent demands. Discrete models such as discrete element model (DEM) and particle method are expected to enable precisely simulation of the discontinuous and inhomogeneous phenomena in the recent operating conditions. With discrete models, microscopic information on each particle in the packed bed can be obtained in addition to the overall phenomena in the blast furnace. Visual information for understanding in-furnace phenomena can be also obtained with high spatial resolution. Liquid dripping and the movement of fines in the lower part of the blast furnace can be simulated with high accuracy by using DEM and particle methods such as the Moving Particle Semi-implicit Method (MPS). Moreover, the optimum bed structure for low reducing agent operation is being clarified by application of the Eulerian-Lagrangian method. This review summarizes recent progress on the mathematical models based on the discrete model.
\end{abstract}

KEY WORDS: ironmaking; blast furnace; mathematical model; discrete model; discrete element method; particle method.

\section{Introduction}

The blast furnace is the core process in the steel works. Stable operation is demanded at all times in order to secure the specified production rate and provide a smooth supply of pig iron with consistent quality to the steelmaking process. On the other hand, the blast furnace is also a complicated moving bed reactor comprising mainly three phases, i.e., solid, gas, and liquid, and includes temperature regions from normal temperature to temperatures exceeding $2000^{\circ} \mathrm{C}$. In order to achieve stable operation, it is necessary to collect information on the heat transfer, reaction, and other phenomena in the 3-phase system in the blast furnace, and to perform appropriate operational design and analysis corresponding to the purpose. However, the measured data that can provide a knowledge of the phenomena in the blast furnace are extremely limited. Accordingly, high importance has historically been placed on research, development, and use of mathematical models of the blast furnace for prediction and analysis of the phenomena in the furnace and operational design. In recent years, many large-scale blast furnaces with inner volumes exceeding $5000 \mathrm{~m}^{3}$ have been

* Corresponding author: E-mail: ariyama@tagen.tohoku.ac.jp DOI: http://dx.doi.org/10.2355/isijinternational.54.1457 constructed mainly in Japan. Efforts to realize low reducing agent rate operation, diversification of charging methods for various burden materials, ${ }^{1)}$ study of application of new burden materials such as Ferro-coke, ${ }^{2)}$ and the search for more fundamental low-carbon technologies for the future are underway, preconditioned on stable operation of these largescale blast furnaces. From this background, there is a heightened need for research and development of new blast furnace models which make it possible to obtain local information specific to blast furnaces with high precision.

In the past, active research and development were carried out on blast furnace models based on continuum modeling. Those efforts produced results that contributed to understanding the blast furnace as a whole. A certain degree of completion can also be seen in 4-phases models which include fine powdery materials in addition to solids, gases, and liquids, and a grasp of the macroscopic process variables in the blast furnace has substantially been achieved. ${ }^{3,4)}$ On the other hand, because blast furnace is regarded as a packed bed characterized by movement of individual particles, the description of particle motion in the blast furnace, which forms basic the structure of the blast furnace model, should approach the actual phenomena as closely as possible. Considering these recent needs, high expectations are placed on models that can directly reflect individual particle 
information. With progress in computing capability in recent years, it has become possible to construct the packed bed structure in the blast furnace from positional information in particle units by applying the Discrete Element Method (hereinafter, DEM), which is a representative discrete method, and it is now possible to visualize the solid flow from burden distribution formation at the throat to the ununiform region in the vicinity of the tuyeres. ${ }^{5)}$ Likewise, model analysis techniques suitable for liquid phase transfer phenomena, which display an irregular mode of motion, have also been developed for the droplet flow in the lower part of the blast furnace by applying the particle method. ${ }^{6}$ ) The basic research on modeling of the 4-phases (i.e., solid, gas, liquid, fine particles) in the blast furnace, including DEM, was summarized by Dong and A. Yu et al. in 2007. ${ }^{7}$ Discrete methods for blast furnace modeling are now in the developmental stage, research and development on related models is gradually progressing, and new results are continuing to appear. ${ }^{8)}$ The present paper describes recent trends in research on blast furnace modeling for application to actual blast furnaces and blast furnace analysis based on discrete approaches, together with the outlook for the future.

\section{Trends of Model Development and Current Needs}

A summary of the progress of research on blast furnace modeling is shown in Fig. 1. Historically, mathematical models based on differential equations for the mass and energy balances in the furnace can be traced back to a 1dimensional model proposed by Yagi et al. around 1970. ${ }^{9}$ This is called the "Muchi model." That approach was later developed to 2-dimensional and 3-dimensional models and 3-dimensional unsteady state models. ${ }^{10,11)}$ Moreover, in parallel with development of pulverized coal injection (PCI), 4phases models were also proposed, in which fine particles were added to the conventional three solid, gas, and liquid phases. ${ }^{3,4)}$ Expansion of the spatial dimension and treatment of an increased number of phases made it possible to obtain an useful information and produced many beneficial results.

Returning to the essential phenomena in the blast furnace, the blast furnace is a packed bed comprising particles of ore and coke. After the burden is charged, the burden materials gradually descend through the furnace, passing through the cohesive zone, and form a furnace core called the "deadman" at the lower furnace area. Approaching the raceway, the molten material takes on a discontinuous mode of movement, and the coke content is consumed in the raceway. The packed structure is determined by the particle motion and changes in properties during this descending. Gas flows and liquid flows in the blast furnace are governed by that structure. Accordingly, as mentioned in the Introduction, the description of the motion of the constituent particles of the packed bed plays an important role in blast furnace models.

Figure 2 shows the needs in blast furnace models in recent years. As shown in this figure, as a result of the adoption of coke mixed charging and diversification of burden materials, which include carbon-iron ore composites, Ferrocoke and similar hybrid materials, in addition to layered charging, greater flexibility in controlling the layer structure and the capability to respond to the changes in particle properties are now considered necessary. Moreover, with the trend toward low reducing agent rate operation, which is preconditioned on the large-scale blast furnace, more detailed information is necessary regarding the formation of the deadman in the lower part of blast furnace, ununiform solid phase motion around the deadman, and other related phenomena. As the droplet dripping phenomenon in the lower part is also a repeated discontinuous phenomenon involving dispersion and coalescence of the droplets and the behavior of the liquid phase is related to the productivity and stable operation of the blast furnace, a model which can express those characteristics is desirable. The basic structure of conventional models generally approximated a quasi-fluid for solids and used a continuum model which depended on a fixed grid for liquids and fine particles. As a result, the discrete 3-dimensional information which is specific to the blast furnace process tended to be "smoothed." On the other hand, if these phenomena can be expressed mathematically without losing that information, it is also possible to respond to recent needs.

\section{Analysis of Particle Motion in Blast Furnace by DEM}

\subsection{Features and Subjects of DEM and Application to the Blast Furnace}

DEM, in which particle motion is treated discretely, is widely used in motion analysis of discontinuous solid flows

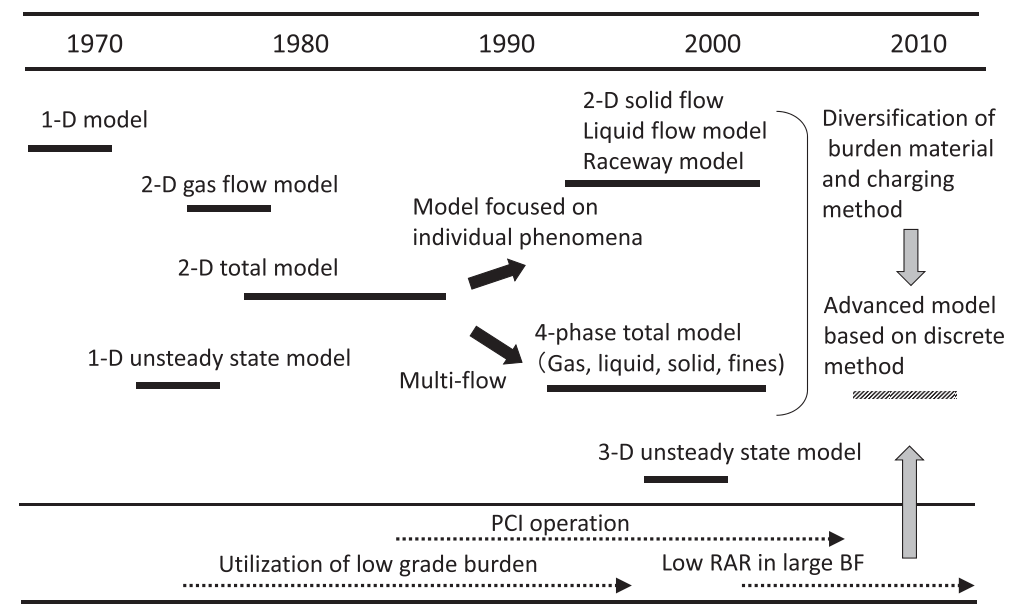

Fig. 1. Progress of mathematical models of blast furnace. 
and enables unsteady tracking of the behavior of particles in the calculation region by solving equations of motion for all particles. A DEM model based on the particle element com-

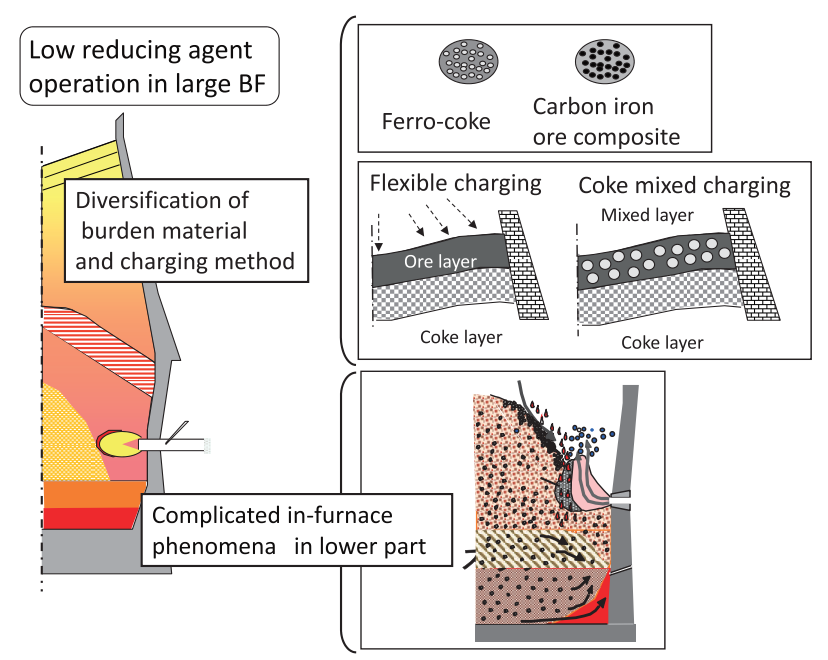

Fig. 2. Change of operating condition and in-furnace phenomena.

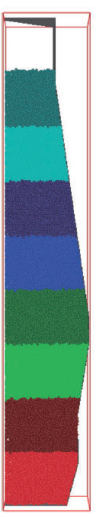

(a)

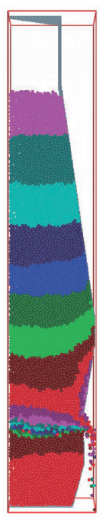

(b)

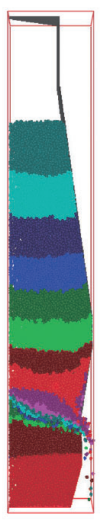

(c)

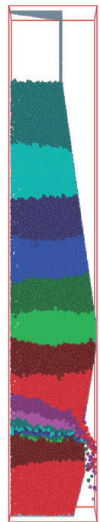

(d)

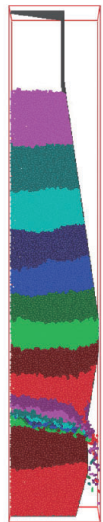

(e)
Fig. 5. Pie-slice model simulation results((a) initial packing, (b) spherical, (c) non-spherical 1, (d) non-spherical 2, (e) nonspherical 3). ${ }^{14}$

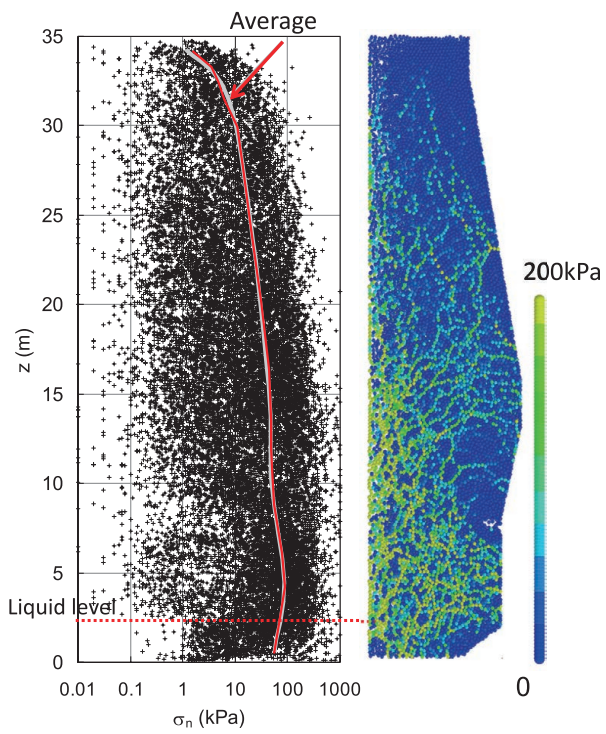

Fig. 6. Calculated normal stress distribution and stress field by DEM. ${ }^{18)}$ prising the blast furnace is shown in Fig. 3. As shown in this figure, the fundamental equations in DEM consist of a translational motion equation and a rotational motion equation, which uses the stress and moment from the contact points between individual particles and between particles and the furnace wall. ${ }^{12)}$ Drag force is calculated by a Voigt model, which is approximated by a spring, dashpot, and frictional slider. By extension of this fundamental form, simulation of the solid motion in the whole blast furnace based on the dynamic behavior peculiar to the individual particles is pos-

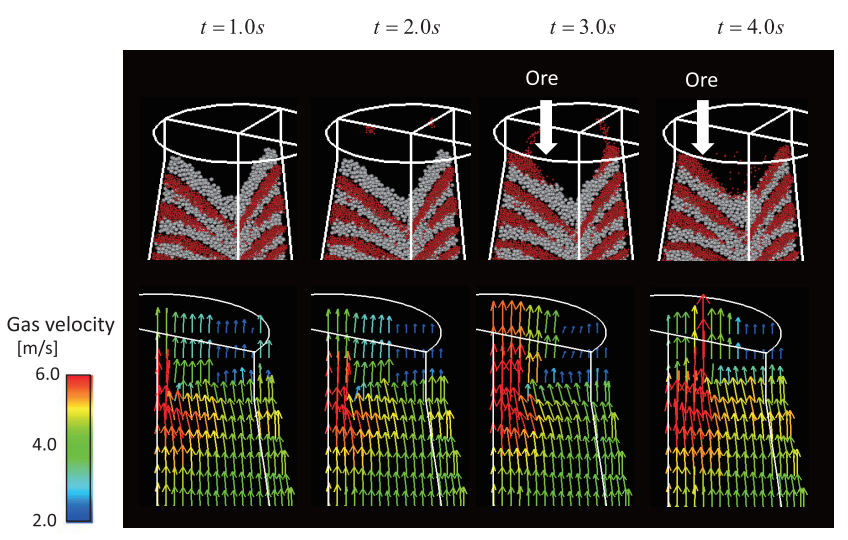

Fig. 14. Transient gas velocity change at throat during ore particle charging.

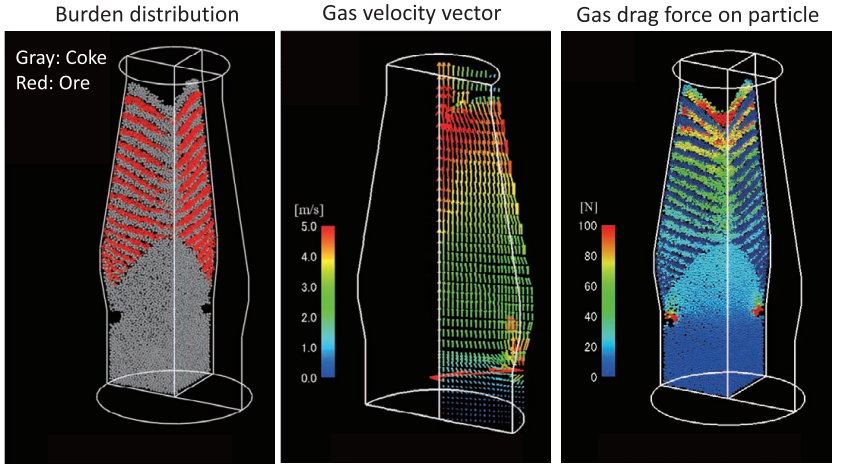

Fig. 15. Burden distribution, gas velocity and gas drag force calculated by DEM-CFD model.
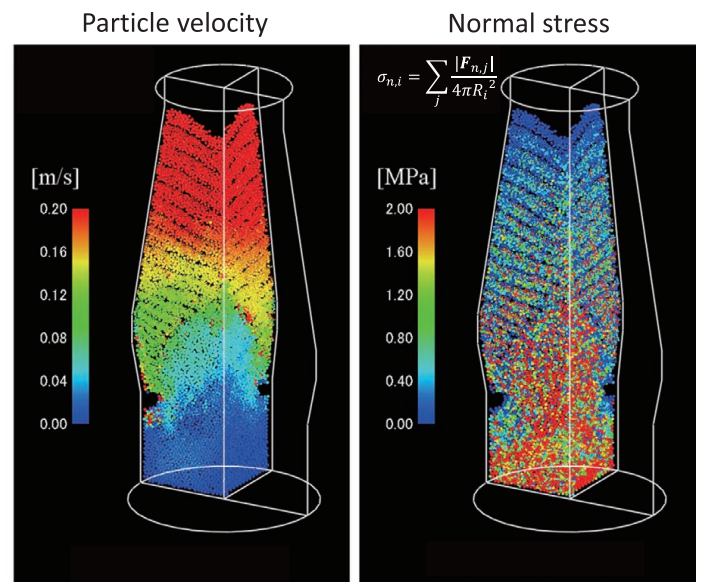

Fig. 16. Particle velocity and normal stress gas calculated by DEM-CFD model. 


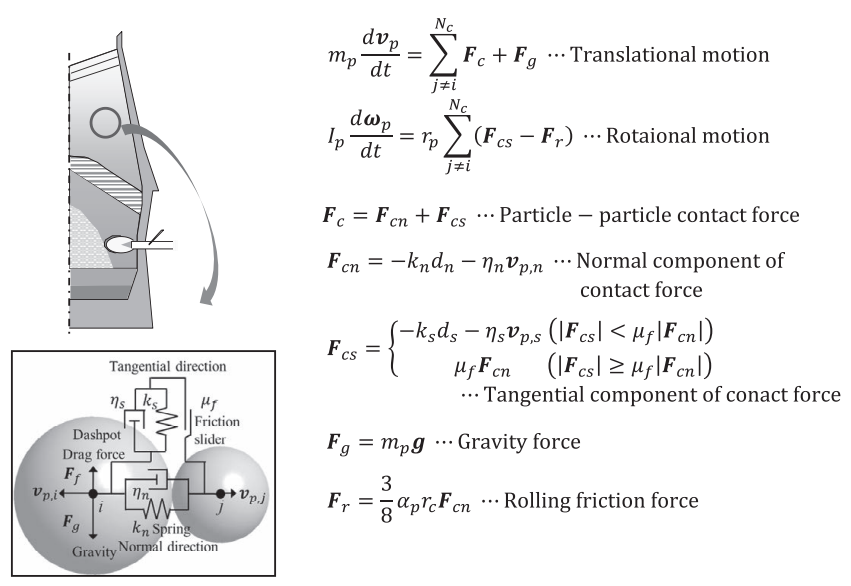

Fig. 3. Element of discrete element model in blast furnace and fundamental equations of DEM.

sible from the furnace top to the raceway.

In recent years, the applicability of DEM to the blast furnace has expanded as a result of the development of calculation method conforming to blast furnace conditions and progress in calculation speed and computer capacity. The constituent parameters in DEM are few in number, which is advantageous for performing calculations, but conversely, the decision of those parameters becomes critical and there are some subjects to be considered for the application of DEM to the blast furnace. In particular, the number of particles that can realistically be treated in DEM calculations is a practical problem, and because conventional DEM treats particles as spherical, whereas sinter, coke, etc. are irregular in shape, how to express the properties of irregularly-shaped particles also becomes an issue.

Regarding calculation speed, the value of Young's modulus is an influential parameter in the fundamental equations of DEM, and is related to improvement of DEM calculation speed by way of the computational step interval. Essentially, the values of mechanical properties such as Young's modulus should be set to the characteristic values of the particles. Ueda et al. carried out a study in which Young's modulus was changed over a wide range, from 0.2 to $5.0 \mathrm{GPa}$, and showed that it is possible to accelerate calculations by selecting the value of Young's modulus considering the possibility that this is also reduced in macroscopic analyses of the blast furnace as a whole. ${ }^{13)}$ Moreover, the total number of particles in the blast furnace reaches several 100 million, which exceeds the range of practical DEM calculations. Therefore, when calculating phenomena in the actual blast furnace, computational workability is improved by reducing the number of particles by adopting a coarse-grained approximation method such as clustering and reducing the calculation region by simultaneously using a periodic boundary condition that considers symmetry. Regarding the treatment of irregularly-shaped particles, in a study of a small-scale blast furnace, Adema et al. expressed the shapes of the irregular particles by spherical aggregates, as shown in Fig. 4, and studied the effect on descent behavior in the blast furnace. ${ }^{14)}$ The results are shown in Fig. 5. It has been reported that the effect of the particle shape appears in the height of the deadman in the lower furnace and the particle flow near the wall. Akashi et al. also proposed a similar

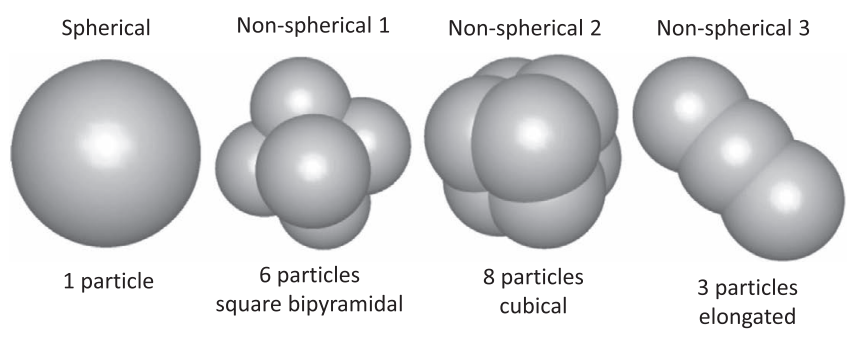

Fig. 4. Particle shapes and dimensions. ${ }^{14)}$

method in which the particle shape is expressed by aggregates of multiple particles. ${ }^{15)}$ In DEM, it is also possible to consider the particle shape by selection of the contact friction coefficient and the rotational friction coefficient. The authors selected appropriate values for the contact friction coefficient and the rotational friction coefficient by comparison with the results of a small-scale cold test, and showed that the effect of the shape factor can be expressed approximately by this method. ${ }^{16)}$ Thus, various options are available, depending on the purpose and range of the calculation.

\subsection{Calculated Results by Application to the Blast Fur- nace}

Research by Kajiwara et al. ${ }^{17)}$ may be mentioned as the beginning of application of DEM to the blast furnace. In a study of a small-scale 2-dimensional model, DEM was applied to analysis of particle motion during the formation of the burden distribution from the bell top, and the results were compared with experimental results, showing the possibility of application. Subsequently, with the above-mentioned progress in computing capability, the range of applications and application conditions expanded, and calculation of blast furnace-scale conditions and the blast furnace as a whole became possible. Nouchi et al. focused on analysis of the stress between particles in the blast furnace by DEM calculation and, as shown in Fig. 6, expressed the stress distribution in the blast furnace as an stress field having a wideranging numerical distribution. ${ }^{18)}$ At the same time, they also showed formation of a reticulate stress network by DEM calculation. These types of knowledge are useful information for analysis of particle collapse in the blast furnace. Ho et al. demonstrated the validity of DEM while comparing the collapse of the lower layer during charging on a bell-less blast furnace charging plane and the results of a cold experiment. ${ }^{19)}$ Mio et al. carried out an analysis of particle motion and particle segregation for each particle diameter in the hopper and on the bell-less chute by appropriate use of various rotational friction coefficients corresponding to the particle size. ${ }^{20)}$ As an extension of that work, a 3-dimensional simulation of the burden distribution formation process in the bell-less blast furnace was also developed. ${ }^{21)}$ As an example of these calculations, Fig. 7 shows the results of calculation of the simulated burden distribution formation in the blast furnace throat. Yu et al. performed an analysis by DEM calculations which considered the particle size distribution for pellet particle penetration from above accompanying burden descent in the vicinity of the throat. ${ }^{22)}$ Figure 8 shows an example of those calculation in comparison with a cold experiment. Although direct observation under the surface layer at the throat is difficult, 


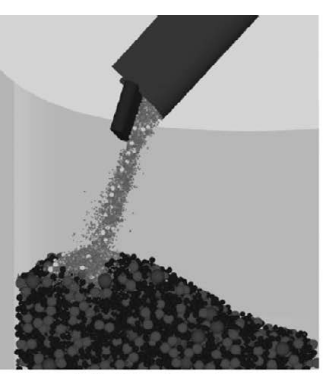

(a) 4th charging

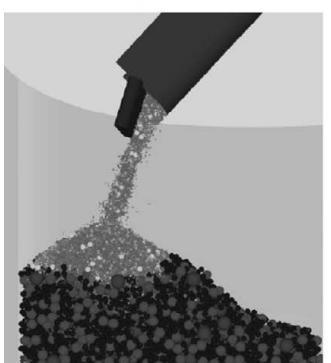

(c) 12th charging

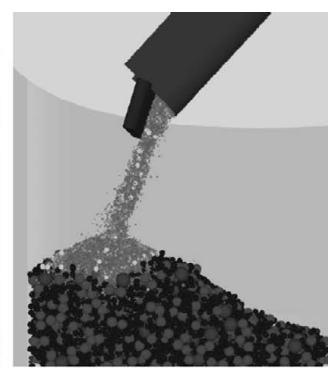

(b) 8th charging

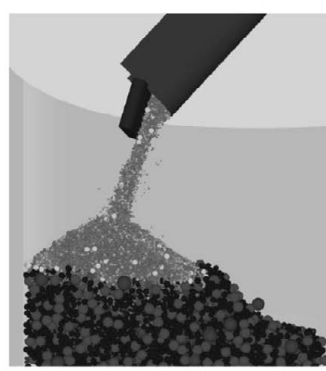

(d) 16th charging
Fig. 7. Snapshots of cross section of charged material from chute. ${ }^{21)}$
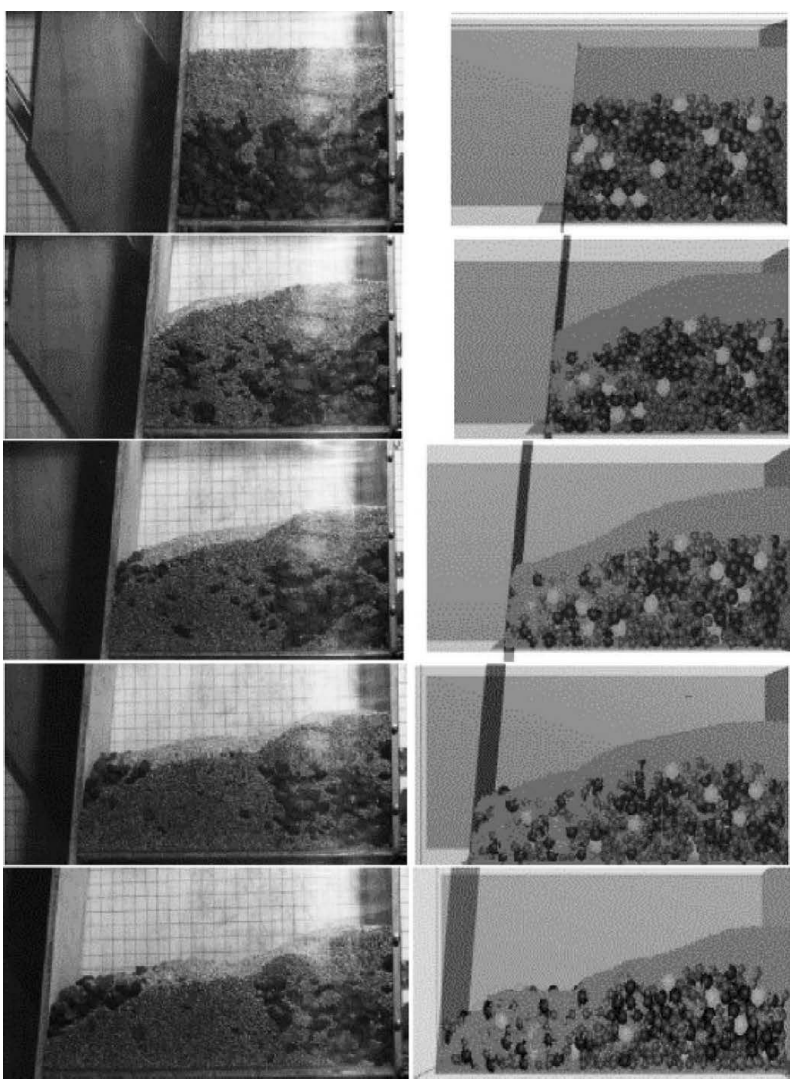

Fig. 8. Comparison of experimental and DEM simulation results for expansion experiment with pellet layer on coke layer (coke fractions are illustrated in dark gray (small), black (intermediate) and white (large), while pellets are depicted in light gray). ${ }^{22)}$

a DEM model can provide a large amount of information, including 3-dimensional information, on transient distribution formation, particle size segregation in the layers, particle penetration, and other behavior, and thus is useful for improvement of burden distribution control.

Because DEM expresses the total system based on the (a)
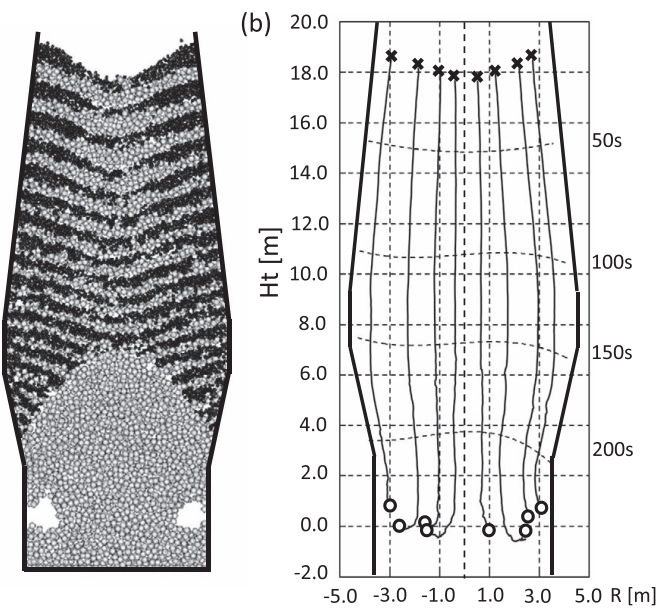

Fig. 9. Descending behavior of burden in blast furnace ((a) shape of layers, (b) calculated stream line).

dynamic interaction between individual particles, it is easy to set boundary conditions such as the vessel shape, distinguish stagnant regions and fluid regions. Accordingly, DEM can also respond flexibly to analysis of solid descent motion, which is strongly anisotropic in spatial terms and is ununiform in the lower furnace, and asymmetrical irregular solid motion. Figure 9 shows the burden distribution in a small-scale blast furnace; Fig. 10 shows an analysis of particle motion when half of the tuyeres are blocked. ${ }^{5)}$ Figure 9 shows the results of a calculation under standard conditions. The packed structure in the furnace formed by layered charging can be reproduced, and stream lines and time lines can be recognized from the tracks of designated particles. Tuyere blockage is a trouble which occurs occasionally during blast furnace operation, and analysis of the effect in the upward direction by the tuyere blockage is critical for early startup. In the calculation results in Fig. 10, in which certain tuyeres were set as inactive, a stagnant zone forms directly above the inactive tuyeres, but the effect of tuyere blockage gradually decrease in the middle part of the shaft, and the speed of burden descent increases on the opposite side from the inactive tuyeres. These points are in good agreement with the results of a cold experiment in the past. ${ }^{23)}$ Since DEM is a unsteady calculation method, it is also possible to obtain information on discontinuous phenomena, for example, showing slip-like descent in irregular particle transfer and locations where slip frequently occurs during unstable operation. Figure 10(c) shows the ratio of shear stress and normal stress as a slipping factor, Sli. ${ }^{5)}$ It can be estimated that unstable descent regions with a high slipping factor, Sli, tend to occur easily in locations where changes in particle speed and direction are large, such as the back of the raceway, the area near the wall in the bosh.

\section{Development to DEM-CFD Model}

\subsection{Simultaneous Analysis of Solid and Gas Motion}

Simultaneous analysis of solid and gas motion in a packed bed is possible by coupling the particle information obtained by DEM, such as the particle position, void fraction distribution, and a gas flow analysis by computational fluid dynamics (CFD). Simultaneity with the equations of 


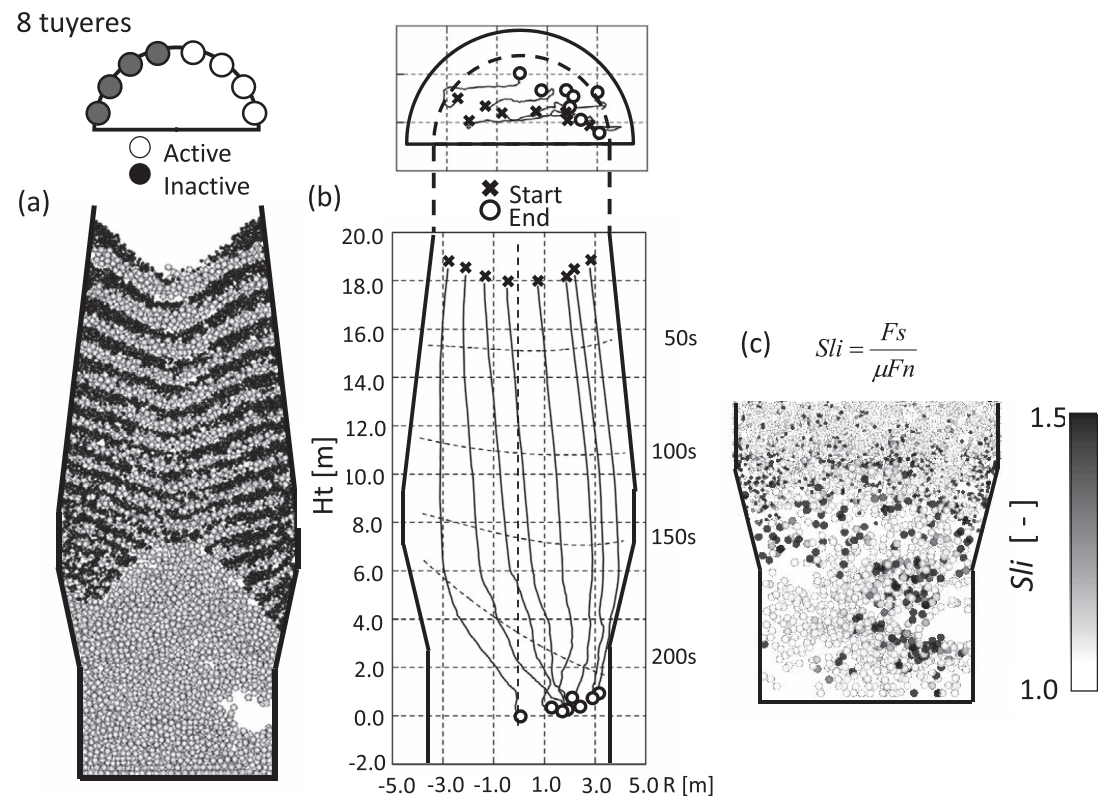

Fig. 10. Descending behavior of burden in blast furnace when half of tuyeres are inactive((a) shape of layers,(b) calculated stream lines, (c) slipping factor).
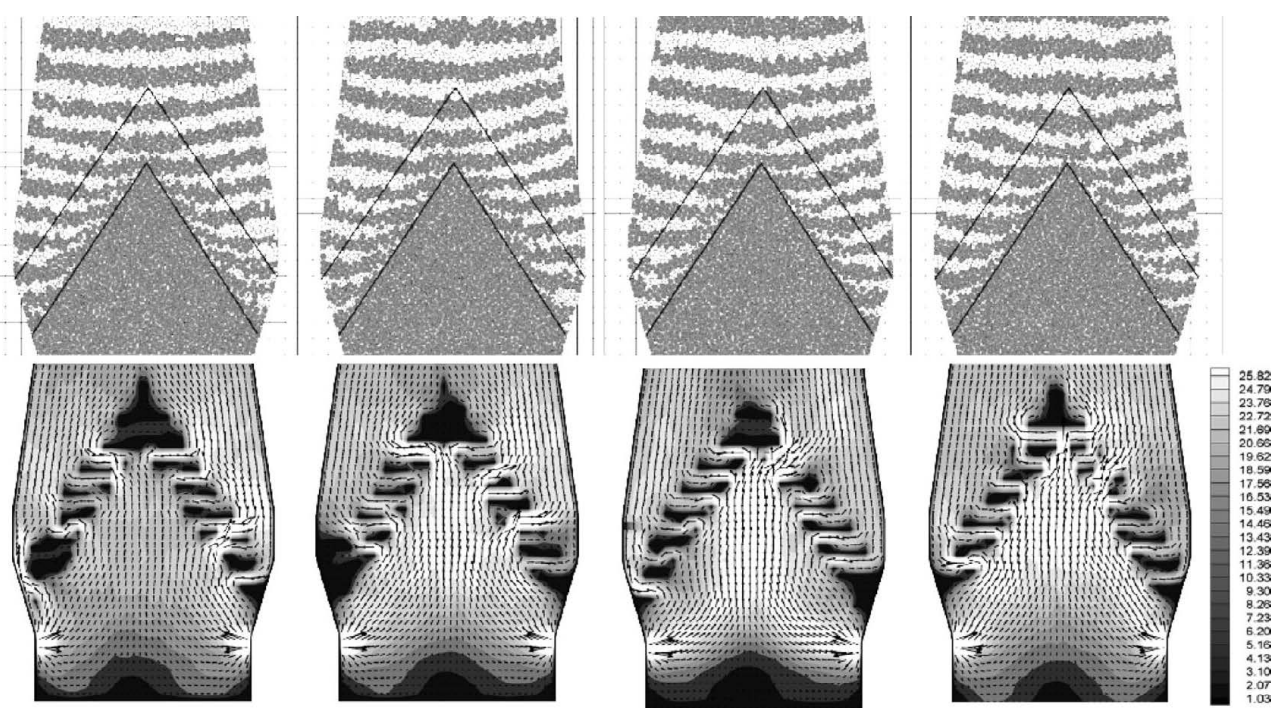

Fig. 11. Snapshots of solid flow and corresponding gas flow in cohesive zone. ${ }^{25)}$

motion for the gas phase can be realized by introducing the force of interaction between the gas and particles in the fundamental equations of motion of DEM. Nakano et al. performed a stability analysis of particle motion in the vicinity of the raceway under small-scale model conditions. ${ }^{24)}$ Zhou et al. performed a simultaneous analysis of the particle motion and gas flow in the lower furnace under experimental blast furnace scale conditions (Fig. 11). ${ }^{25)}$ In a study at actual blast furnace scale, Umekage et al. calculated the coke motion and gas flow in a $9^{\circ}$ sectoral-shape calculation region in the lower part of the blast furnace and analyzed the effect of scaffoldings (buildup of material on the furnace wall, causing unstable gas and solid flows). ${ }^{26)}$ An example of this calculation is shown in Fig. 12. In research continuing from that work, a detailed analysis of the particle motion and gas flow was performed for a $90^{\circ}$ sectoral-shape part of the lower furnace, which included $16 \times 10^{6}$ particles. ${ }^{27)}$

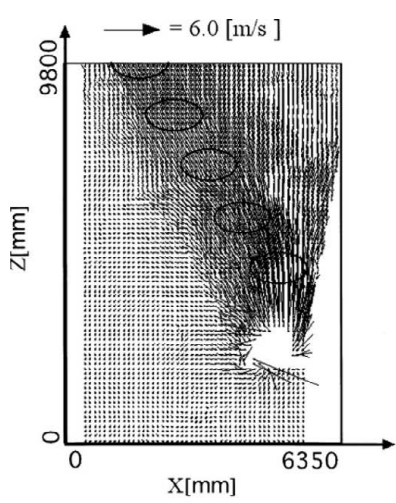

a) With scaffoldings

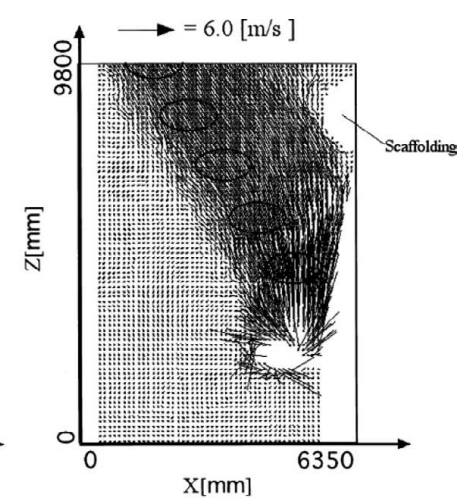

b) Without scaffoldings
Fig. 12. Calculated instantaneous coke particle velocity vector on the actual blast furnace for 7 degree downward tuyere direction (a) without scaffoldings, b) with scaffoldings). ${ }^{26)}$ 


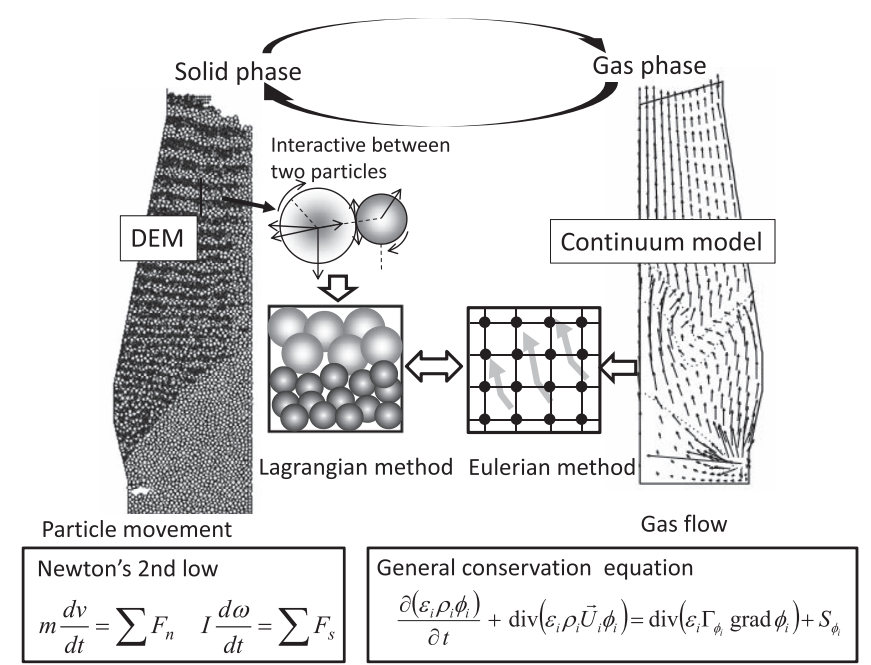

Fig. 13. Combination of discrete element model of solid movement and continuum model of gas flow.

In calculations of the total blast furnace, DEM calculation information (Lagrangian method), such as the ore and coke layer structure, etc., must be transcribed to the calculation mesh of CFD (Eulerian method) with high accuracy. That is, the discrete information in particle units obtained by DEM calculation, for example, the position of each particle comprising the layer, the void fraction, and the like, is converted with high precision to CFD grid information, a gas flow calculation is performed, and then the DEM calculation is repeated again, this time considering gas drag force. Figure 13 shows the concept of this calculation procedure. ${ }^{28)}$ Since the particle information of the equations of motion treated in the CFD calculation is based on the actual particle diameters, ingenuity is required in case a coarse-grained approximation is performed in the DEM calculation. Natsui et al. proposed a method of transcribing 3-dimensional particle information into the CFD computational mesh without loss, in which a study space is provided by considering the 3dimensional geometrical arrangement with surrounding particles, centering on a particle of interest, and weights are assigned to the void fractions in the vicinities of individual particles depending on the distance between the cell and particle center. ${ }^{28)}$

Figure 14 shows the results of a gas flow calculation during ore charging in the blast furnace throat as an actual example of a 3-dimensional DEM-CFD calculation for an actual blast furnace. ${ }^{28)}$ The fact that fluidization occurs transiently at the center of the throat during ore charging was confirmed experimentally at an early date, ${ }^{29)}$ and this phenomenon can be reproduced by this model calculation, in which unsteady particle motion and gas flow calculations are coupled. ${ }^{28)}$ Figure 15 shows the 3-dimensional burden distribution, gas velocity distribution, and distribution of gas drag force on the particles when a gas flow exists across an whole $5000 \mathrm{~m}^{3}$ class blast furnace. Figure 16 shows the particle velocity and normal stress distribution. From the distribution of gas drag force on the particles, a condition in which large gas drag force acts on the parts at the back of the raceway and around the center at the top of furnace can be observed. Similarly, from the particle velocity, it can be understood that a stagnant area of descent appears, which corresponds to the deadman, and from the stress distribution, a large load is concentrated on that deadman region. These results are important information for stable control of the blast furnace.

As an application of this method, a 3-dimensional gas flow analysis was performed for shaft gas injection, which has attracted attention as a future technology for developing low carbon blast furnace. ${ }^{30,31)}$ Figure 17 shows the results of a 3-dimensional gas flow calculation during shaft gas injection in large-scale blast furnace and small-scale blast furnace. A region which is influenced by the gas flow injected from an auxiliary tuyere at the bottom part of the shaft can be confirmed, and it can be understood that this region of influence differs depending on the inner volume of the blast furnace. In small-scale blast furnace, the injected gas can relatively reach the center region of blast furnace. Although shaft gas injection is an old idea, and cold experiments have already been carried out with a packed bed, ${ }^{32}$ ) observation of the internal gas flow in layers is difficult. With this simulation, the effect of gas penetration can be predicted, considering the layered structure of the packed bed and the 3-dimensional placement of the auxiliary tuyere. Quantitative results were also obtained, including, for example, the fact that the region of influence depends on the relative quantity ratio of injected gas. ${ }^{30)}$

\subsection{Modeling of Cohesive Zone}

The cohesive zone in the blast furnace is a critical region for evaluation of furnace permeability. In the cohesive zone, reduction of ore particles proceeds, and at the same time, the particles undergo softening and shrinkage while affected by the load of the upper burden material. Modeling of changes in properties such as this softening and shrinkage of ore particles is accompanied by difficulties. Although precise expression of transfer in particle motion is possible in DEM, because the objects of DEM are spherical particles, it is difficult to treat property changes such as softening with the conventional method. Therefore, the authors conceived a method in which the Young's modulus in the DEM calculation in the cohesive zone is changed, referring to the results of permeability changes in the softening test under load, and the decrease in the void fraction of the cohesive zone is expressed by the compression of the particles in this region. In the model, this is expressed by overlapping of the particles. $^{33)}$ The concept of this method is shown in Fig. 18.

The characteristics of the cohesive zone can be evaluated by incorporating the ore softening model described above in the blast furnace. Figure 19 shows the distribution of the void fraction and the gas velocity vectors in the blast furnace under standard conditions when the ore softening model is applied. ${ }^{33)}$ In this calculation, the Young's modulus of the ore and coke was $1.0 \mathrm{GPa}$ in the lumpy zone, and the Young's modulus of the ore was changed to $0.02 \mathrm{GPa}$ in the cohesive zone. It has become possible to visualize gas flows, for example, the distinctive coke slit flow of the cohesive zone, in a selected region of the cohesive zone. As an example of application, Fig. 20 shows the gas velocity vectors in the vicinity of the cohesive zone for two coke rate conditions, namely, $350 \mathrm{~kg} / \mathrm{t}$ and $240 \mathrm{~kg} / \mathrm{t}^{33)}$ In the case of the low coke rate of $240 \mathrm{~kg} / \mathrm{t}$, the permeability in the slit part decreases due to thinning of the coke slit layer, and as a 
result, a gas flow pattern which passes through the slit at the root of the cohesive zone, avoiding the top part of the cohesive zone, and intensified gas flow toward the wall can be observed. Figure 21 shows the distribution of isobar planes. It can be understood that the pressure drop of the cohesive zone has increased remarkably, and there are also issues regarding layered charging in low coke rate operation.

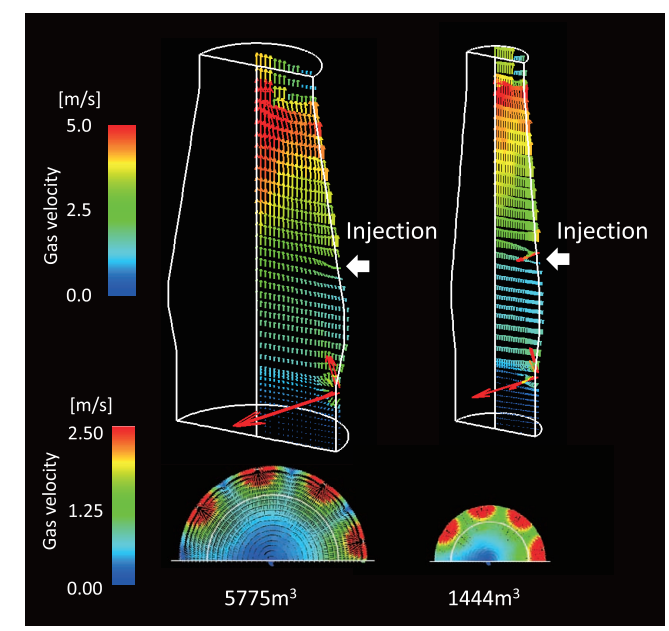

Fig. 17. Effect of shaft gas injection on gas flow in blast furnace.
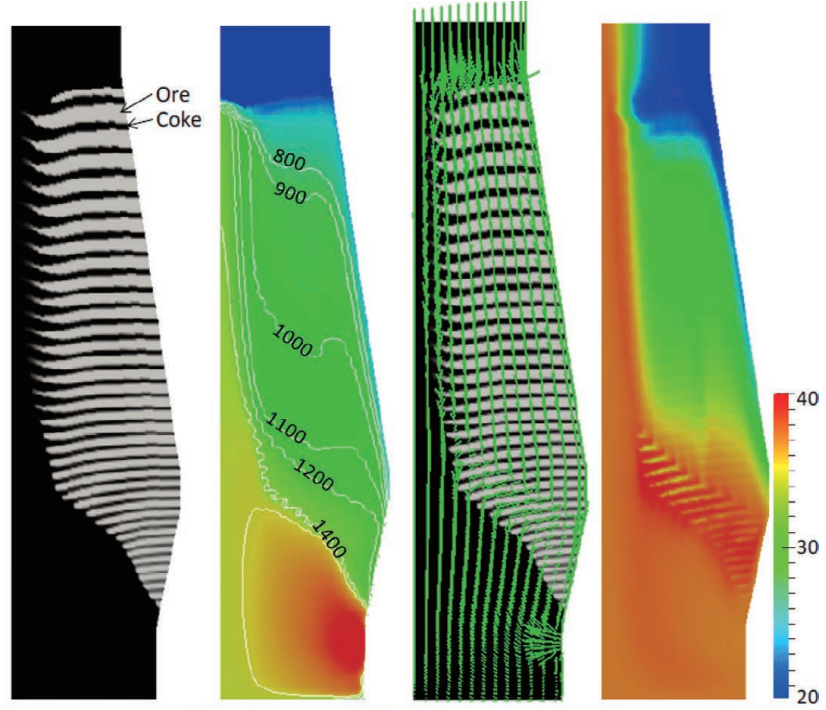

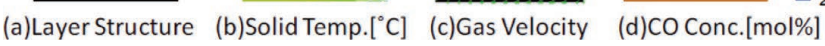

Fig. 22. In-furnace states by BF model. ${ }^{34)}$

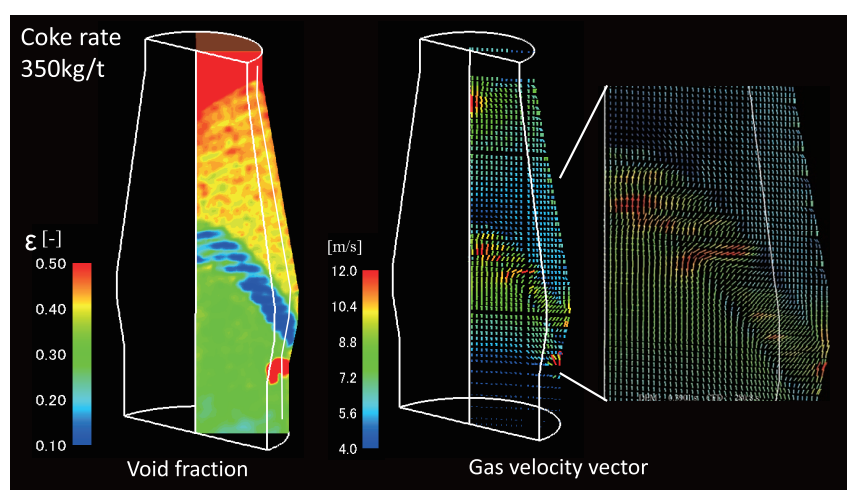

Fig. 19. Void fraction distribution and gas velocity vector considering cohesive zone.

a) Coke rate $350 \mathrm{~kg} / \mathrm{t}$

b) Coke rate $240 \mathrm{~kg} / \mathrm{t}$
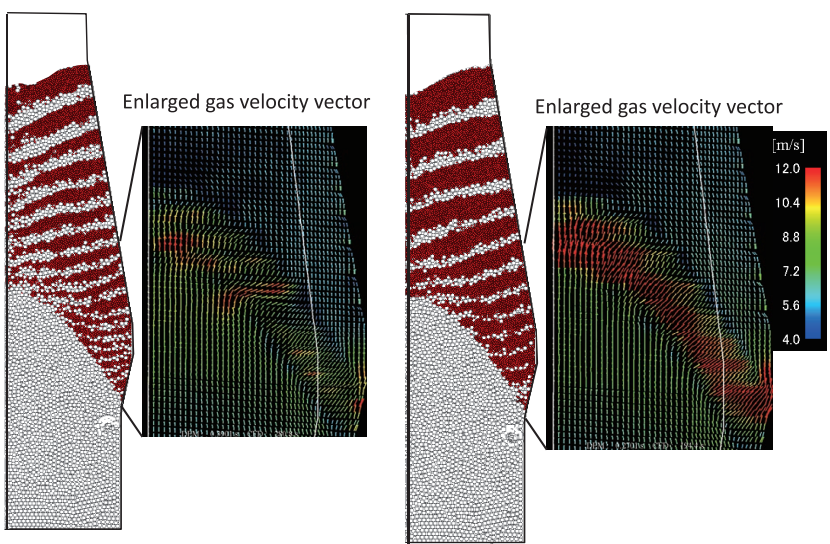

Fig. 20. Burden layer and gas velocity vector for each coke rate condition (red particle: ore, gray particle: coke).

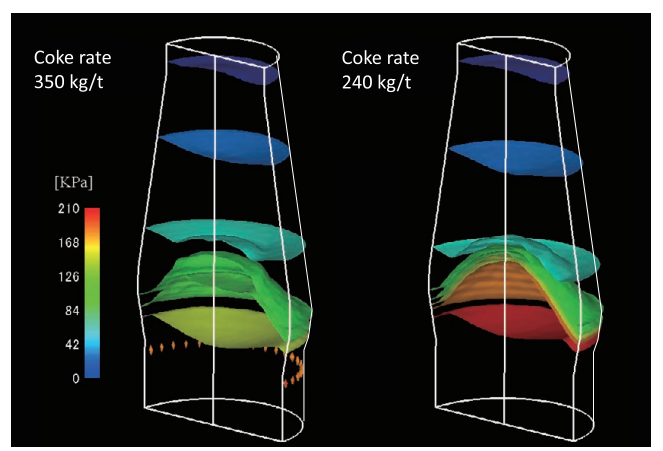

Fig. 21. Isobar planes in blast furnace for each coke rate condition.

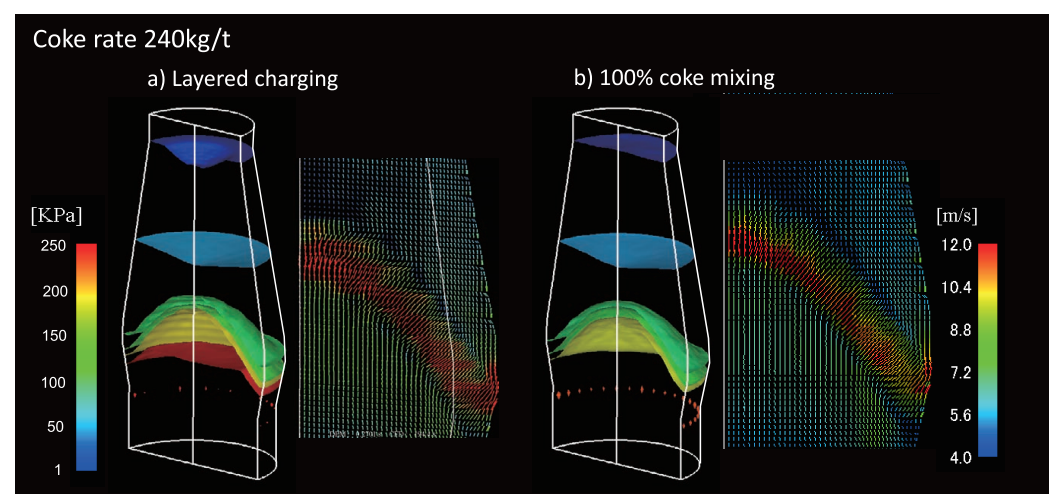

Fig. 25. Isobar planes in blast furnace for layered charging and coke mixed charging. 
In the area of continuum models as well, in recent years a model which can express the layer structure was also developed by Nishioka et al. by applying the volume of fluid method (VOF), which makes it possible to express the interface between burden layers. ${ }^{34)}$ A calculation example is shown in Fig. 22. Although solid phase motion is expressed by a quasi-fluid approximation, this is a comprehensive model which also considers chemical reaction and heat transfer. Because results similar to those for the coke slit flow in the cohesive zone by the DEM model were obtained, this development has attracted attention as a comparison method. However, the subject on the modeling approach to the mixed layer and ununiform boundary between coke and ore layers remains.

\subsection{Application to Coke Mixed Charging}

Mixed charging of coke in ore layers in order to improve the permeability of the cohesive zone has already been implemented at some blast furnaces. ${ }^{1)}$ Considering future low coke rate operation, the thickness of the coke slits in the cohesive zone will become thinner. It is conjectured that coke mixed charging will be effective for improving permeability in the cohesive zone. The effect of this method has already been confirmed in a softening test under load. ${ }^{1)}$ With

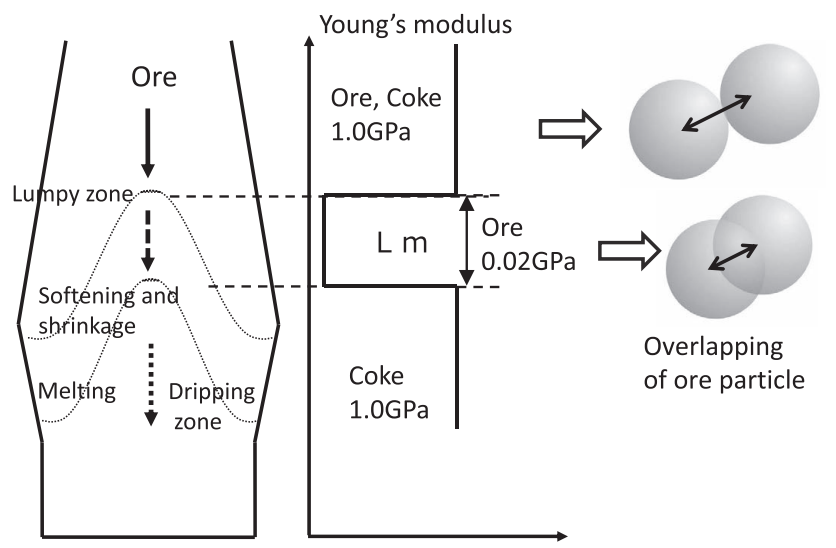

Fig. 18. Modeling of softening and shrinkage of ore particles by DEM.
DEM, it is easy to modify the distribution structure, regardless of whether layered charging or mixed charging is assumed, and quantitative evaluation of actual blast furnaces is possible. As a further development of the above-mentioned cohesive zone model, the authors analyzed the permeability improvement effect during mixed charging. ${ }^{35)}$

As an example of a fundamental evaluation of mixed charging, Fig. 23 shows the results of a DEM calculation of the change in the bed structure and the stress distribution between particles after shrinkage assuming a softening test under load. ${ }^{35)}$ As the coke mixing ratio increases, the shrinkage of the layer becomes more moderate, and the stress distribution displays a condition in which load is received mainly by the coke. Figure $\mathbf{2 4}$ shows the relationship between Young's modulus and the void fraction and relative pressure drop at various coke mixing ratios. These figures demonstrate that the effects of coke mixed charging can be grasped quantitatively by this method. For example, coke mixed charging improves the decrease in the void fraction accompanying softening and shrinkage of the ore, and mixing a volume ratio of $50 \%$ coke can reduce pressure drop by approximately $20 \%$ in comparison with single ore charging. Figure 25 shows the distribution of isobar planes and the change in the gas flow around the cohesive zone in the case of layered charging and the case where $100 \%$ of the coke is mixed with ore under a low coke rate condition of $240 \mathrm{~kg} / \mathrm{t}$. With mixed charging, the pressure drop of the cohesive zone decreases, and an inclined upward gas flow passing through the ore layer of the cohesive zone can be observed. Thus, by utilizing the ability of DEM calculations to respond to setting of the packed structure, it is possible to obtain useful data for designing the optimum layer structure for future low-carbon operation, such as data on the effect of mixed charging in improving the permeability of the cohesive zone.

\section{Model of Heat Transfer and Reaction in Packed Bed Considering Particle Arrangement}

The solid phase reaction in a layer consists of reactions in particle units. Conventionally, this was frequently treated a) Particle arrangement
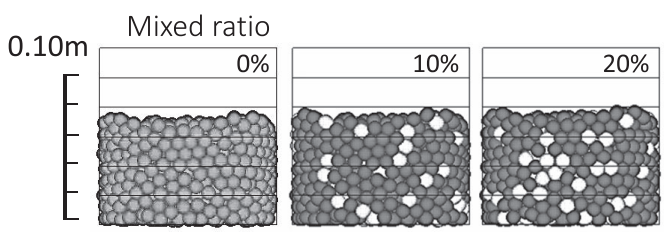

b) Normal stress distribution

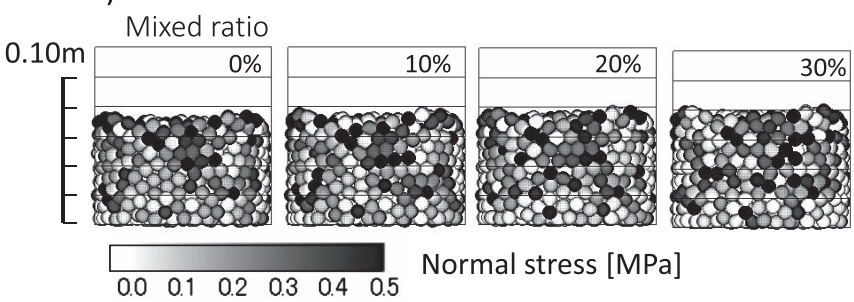

Fig. 23. Simulation of shrinkage behavior of ore particles under coke mixing conditions (vessel diameter: $0.12 \mathrm{~m}$, height: $0.1 \mathrm{~m}$, particle diameter $0.01 \mathrm{~m}$ ).
Young's modulus : 0.02 [GPa]
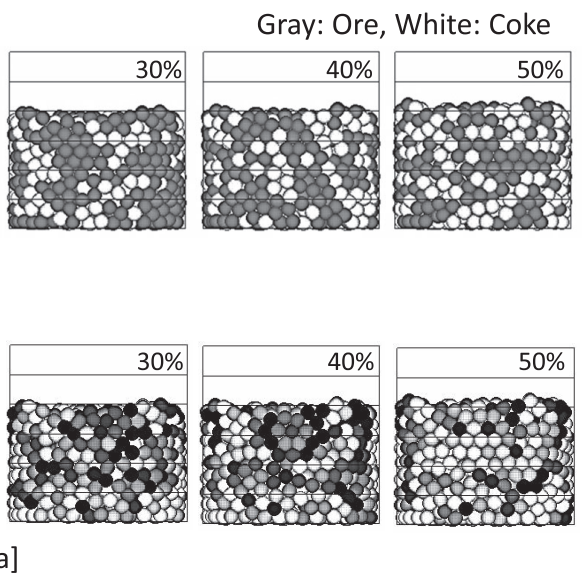

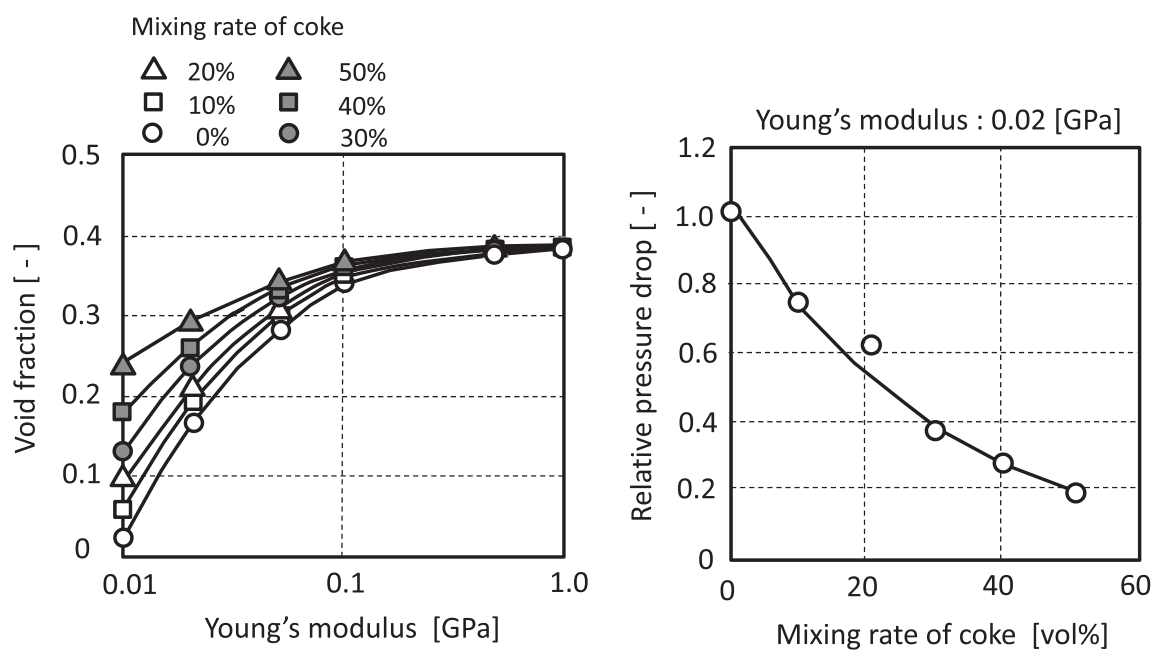

Fig. 24. Influence of coke mixing rate on void fraction and relative pressure drop in packed bed.

additively in the computational grid. Essentially, however, the heat transfer and reactions which take place in a layer are spatially nonlinear phenomena. Heat transfer and reactions are mutually interrelated phenomena, and the changes in their behavior are predicted depending on the local arrangement of particles. In recent years, the idea of controlling the reduction mechanism by using the neighboring arrangement of ore and carbon materials has also been proposed. ${ }^{36)}$ In calculations using a fixed grid, information on the particles between the grids is smoothed, making it difficult to analyze the influence of the local particle arrangement. However, if it is feasible to distinguish particles individually by DEM and incorporate the reaction and heat transfer in each particle under study, and to link this with the gas side transfer phenomena by CFD, a precise understanding of the phenomena in a blast furnace in particle units is possible. Focusing on the Eulerian-Lagrangian method, the authors performed a three-dimensional analysis on the heat transfer and chemical reaction of fixed layer comprising ore and coke particles and having an area approximately $150 \mathrm{~m}^{3}$ as the initial stage. ${ }^{37)}$ The calculation flow is shown in Fig. 26. For heat transfer, this model considers the convective heat transfer, radiation, and particle-to-particle (contact) heat transfer of each particle, and the effect of the heat of reaction of each particle can be reflected by identifying reactions in particle units. This model includes chemical reactions such as reduction of iron ore and coke gasification.

Figure 27 shows the distribution of the reduction degree in the packed layer in particle units after a certain period of time for two conditions, i.e., layered charging (Case A) and mixed charging (Case B). There is no difference in the average reduction degree in the layer in these two cases. Enlarged views are shown in Fig. 28. In layered charging, percolation of ore particles into the coke layer can be seen, and in the ore layer, the reduction degree of the lower ore is slightly smaller than that of the upper particles. The temperature decreases due to the solution loss reaction of the coke layer, which is located under the ore layer, has an effect in the upward direction. Thus, this method is continuing to yield new knowledge, for example, that the reactions and heat transfer have mutual effects on each other, the reaction

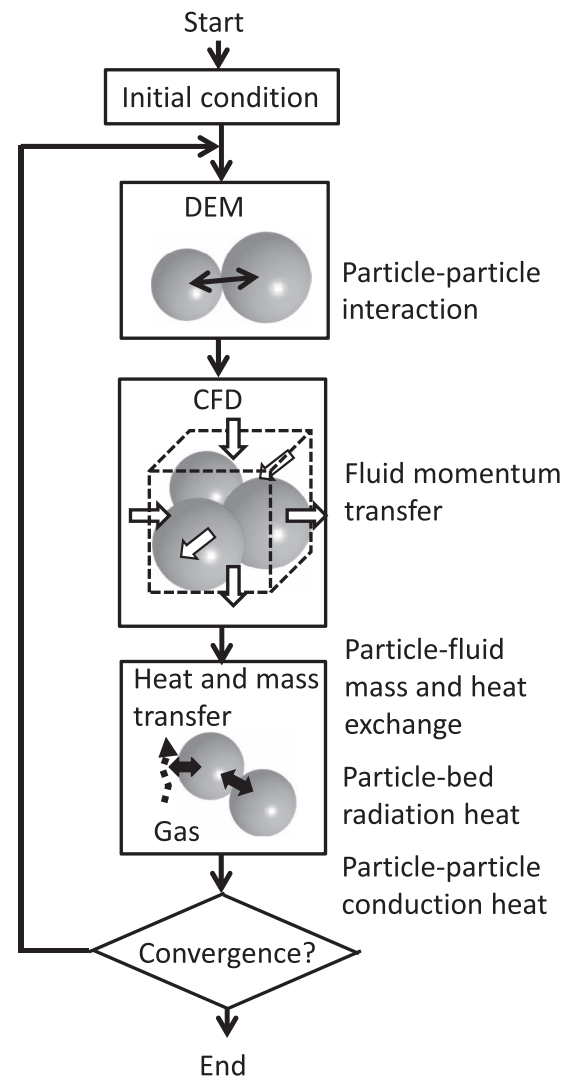

Fig. 26. Calculation flow in Eulerian-Lagrangian method.

in the packed layer proceeds in an extremely ununiform condition, and the design of the layer structure has an important relationship with these phenomena.

An example of a calculation of a heat transfer and reactivity analysis in particle units during mixed charging of high reactivity coke, which takes advantage of the fact that the packed structure can be set arbitrarily, has also been reported. ${ }^{38)}$ Figure 29 shows the calculation results when a mixed layer containing either high reactivity coke or conventional coke was arranged below or above an ore layer. Generally, the progress of ore reduction is delayed by the temperature decrease which occurs when using high reactivity coke. Furthermore, the microscopic interaction between 


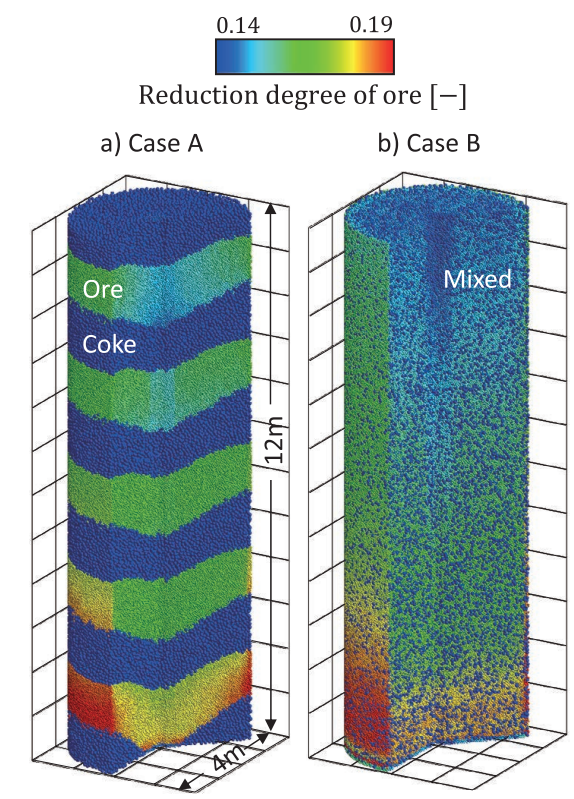

Fig. 27. Distribution of reduction degree in packed bed for layered and mixed structures.
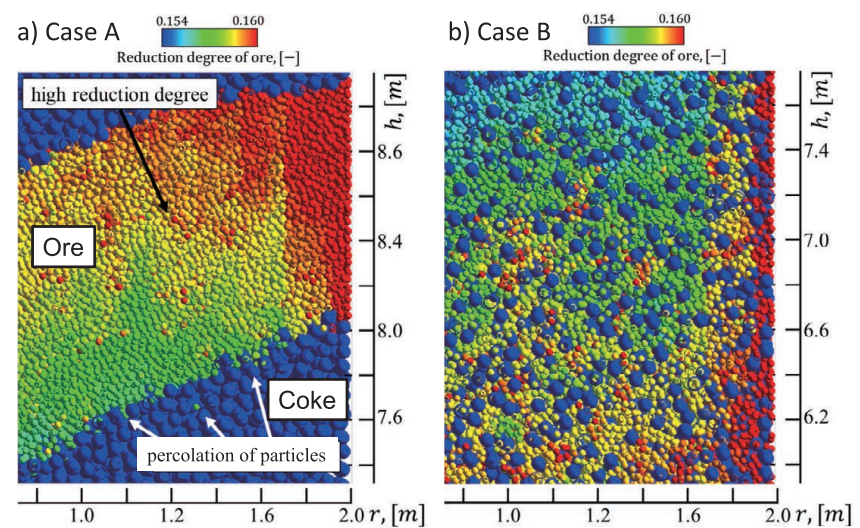

Fig. 28. Enlarged view of reduction degree of ore particles in packed bed.

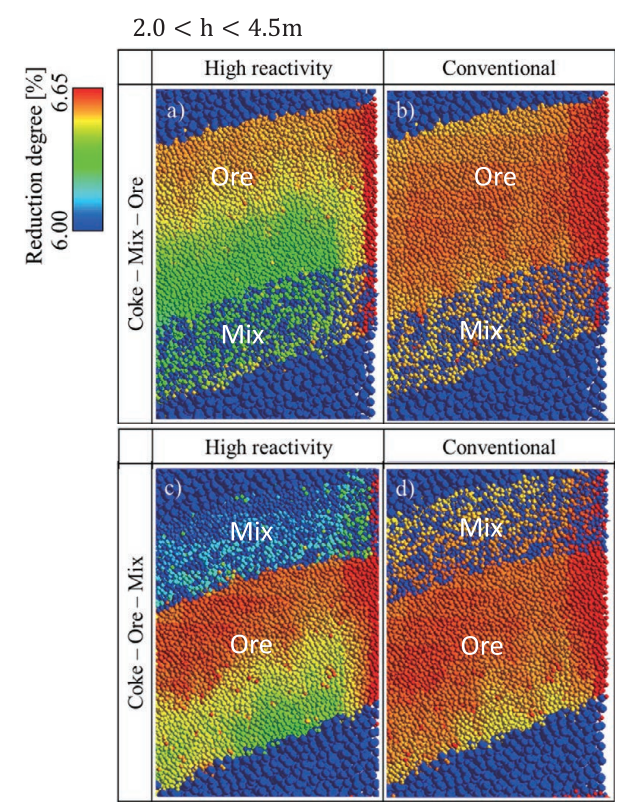

Fig. 29. Enlarged view of reduction degree of ore particles in packed bed including high reactivity coke and conventional coke.
Rolling friction coefficient : 2.5

Friction coefficient : 0.5

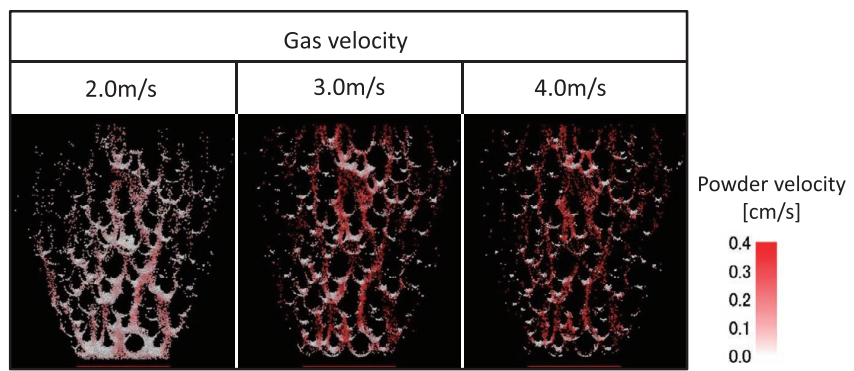

Fig. 33. Powder movements in packed bed under various gas velocity conditions.

\section{$t=1.5 \mathrm{~s} \quad \mathrm{Dp}: 4.4 \mathrm{~mm}$}

\section{$\mathrm{dp}: 0.388 \mathrm{~mm}$}

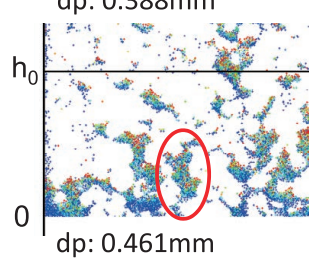

$h_{0} \mid \begin{array}{ll}a & \\ 0 & 0\end{array}$

dp: $0.596 \mathrm{~mm}$
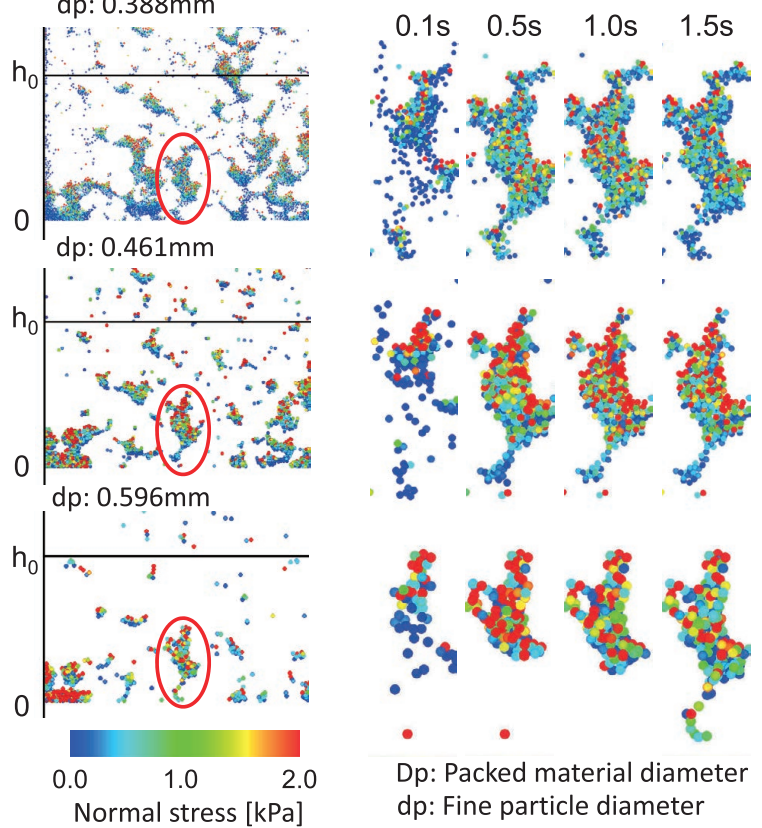

Dp: Packed material diameter $\mathrm{dp}$ : Fine particle diameter

Fig. 34. Snapshots of calculated normal stress distribution of vertical cross section in the packed bed with fine particle flow.

Total model based on discrete phenomena

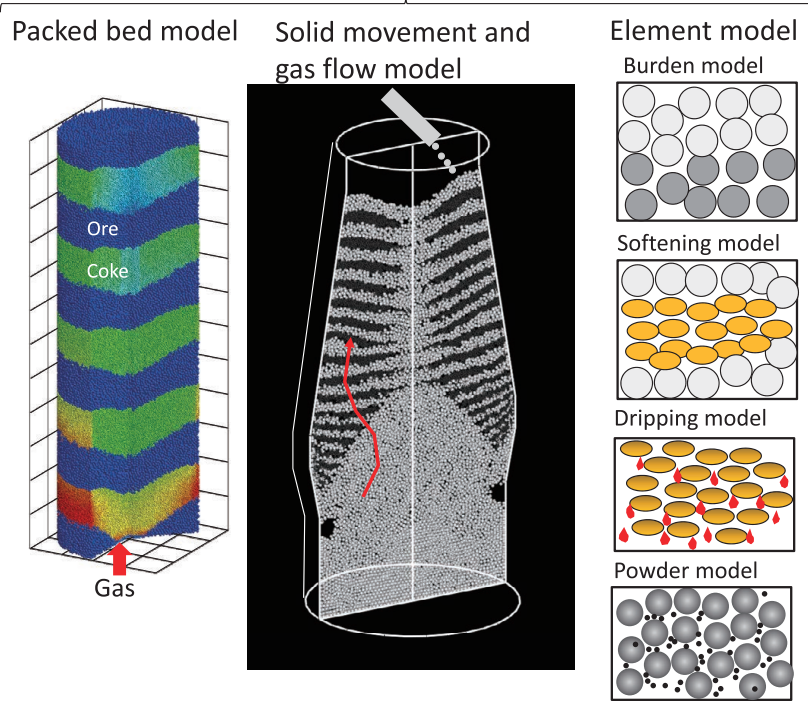

Fig. 35. Various mathematical models based on discrete method for blast furnace. 
heat transfer and the reactions can be understood. For instance, if the high reactivity coke is arranged under the ore layer, the endothermic reaction of coke gasification will cause temperature changes in the ore layer above the coke, and the progress of ore reduction (reduction degree) will also be affected through those changes. This method can be used when determining operational parameters for use of burden materials with new functions, such as the optimum arrangement of high reactivity coke, the relationship with ore reducibility.

\section{Analysis of Liquid Flow and Movement of Fine Par- ticles in the Lower Part of Blast Furnace}

\subsection{Significance of Liquid Flow Model and Conven- tional Model}

In the lower part of the blast furnace, the slag and molten pig iron generated in the cohesive zone drip through a coke packed bed and arrive at the furnace hearth. This is recognized as a critical phenomenon because the flow of the liquid phase during this period affects blast furnace productivity and operational stability, and also affects the composition of the molten iron component. However, with the exception of direct observation by a probe in the area around the raceway, there are virtually no means of observing or measuring the liquid flow in the lower part of the blast furnace. From this viewpoint, an understanding based on numerical models is essential.

In modeling of the liquid flow in the lower furnace, the previous studies used expressions based on a continuum by applying Darcy's Law. ${ }^{39)}$ Later, the liquid distribution was understood stochastically, by considering the liquid flow to be an independent particle motion, and methods for quantifying the liquid flow were developed. ${ }^{40,41)}$ Moreover, a calculation model which couples a continuum model with a distribution model for the liquid has also been researched. ${ }^{42)}$ Regarding the liquid flow as a whole, it is considered that the melt drips in "icicle" form directly under the cohesive zone. $^{43)}$ From observation in cold experiments, this is followed by a liquid flow phenomenon comprising a variety of complicated phenomena which include division/collection and coalescence of droplets, deformation of the droplets, and the like. ${ }^{44,45)}$ In addition, that liquid flow behavior is also affected by wetting behavior between the liquid phase and the coke packed layer.

\subsection{Simulation of Liquid Flow by the Particle Method}

From the viewpoint described above, simulation by the particle method, which is a Lagrangian method, has attracted attention as a method for rationally expressing the dispersion and coalescence of droplets and their interaction with the solid phase.

When using the particle method, mesh setting is unnecessary and analysis of free-surface flows is possible without complex interfacial calculations. The MPS (Moving Particle Semi-implicit) method, ${ }^{46}$ which is one such method, is a technique that was developed for analysis of incompressible free-surface flows, in which the liquid phase is expressed by an aggregate of a finite number of quasi-particle. With this method, it is comparatively easy to describe the movement of a liquid phase including a free surface as a dispersed phase. Many surface tension and wettability models using the MPS method have already been proposed, and in recent years, a 2-dimensional surface tension/wettability model using interparticle potential was proposed. ${ }^{47)}$ This model utilizes the same algorithm as the molecular dynamics (MD) method and has the merit that the algorithm is clear because the interfacial tension between particles is given.

Nishioka et al. performed a macroscopic liquid dripping simulation in the region under the blast furnace cohesive zone by the MPS method. ${ }^{48)}$ Focusing on the packed layer region at designated positions, Kon et al. proposed a liquid flow model using the MPS method, in which wetting and interaction with the solid phase are considered by setting packed particles comprising quasi-particles. The structure and the fundamental equations of the model are shown in Fig. 30. ${ }^{6}$ The results of a calculation of the dispersion and dripping behavior of a single droplet in a packed layer are shown in Fig. 31. ${ }^{6,49}$ ) This figure shows the results for the case where the kinematic viscosity is changed greatly, from the equivalent of slag to that of molten pig iron; from this, it can be understood that the dynamic behavior of the liquid phase varies remarkably, depending on the physical properties of the liquid. As this method allows a high degree of freedom in setting the physical properties of the liquid, and the dynamic deformation of the interface can be understood, it is suitable for analyses of local liquid dripping, like that directly under the cohesive zone. The issues for the future are expansion of the calculation region and interaction with

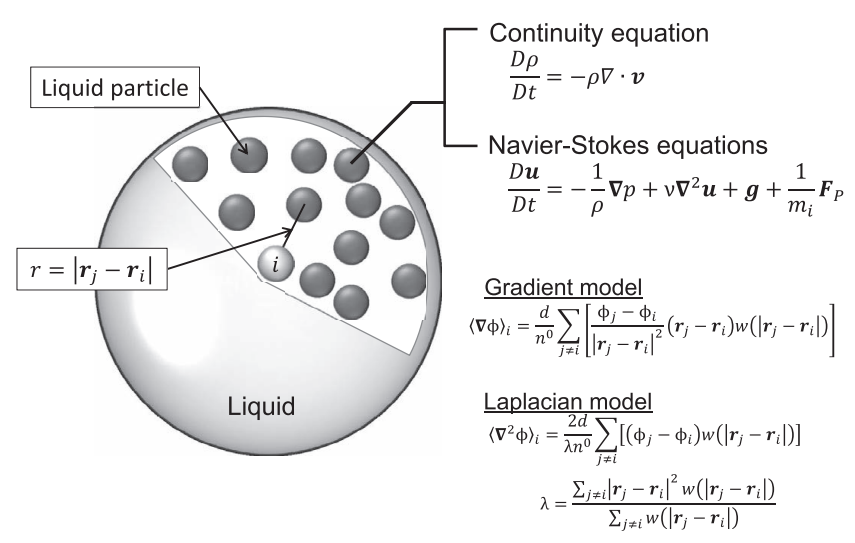

Fig. 30. Concept of MPS method and fundamental equations for modeling.

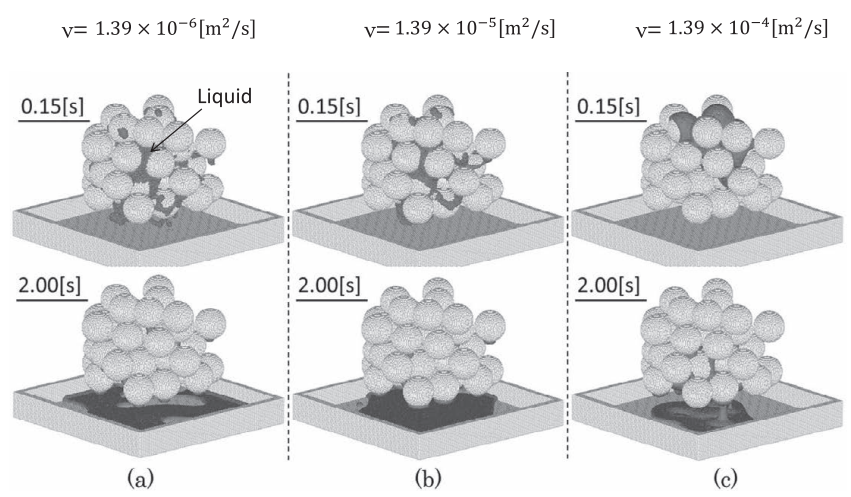

Fig. 31. Effect of viscosity on liquid flow in packed bed calculated by MPS method. 
the gas phase.

\subsection{Modeling of Movement of Fine Particles by the Discrete Element Method}

In the lower part of the blast furnace, in addition to solid, gas, and liquid phases, analysis of the accumulation and motion behaviors of fine particles is important for securing permeability in the blast furnace. In particular, a large amount of unburnt char is generated in the raceway by pulverized coal injection, and this phenomenon affects gas permeability. Therefore, since the $1990 \mathrm{~s}$, motion models for fine particles have been proposed, ${ }^{50,51)}$ and completion of the 4-fluild model for motion analysis of macroscopic particle groups, changes in the void fraction, etc. have been seen. ${ }^{3,4)}$ Moreover, a knowledge of discontinuous phenomena such as local accumulation of fine particles or blockage in the lower furnace, if possible, will clarify the total image of the movement of fine particles.

Focusing on the microscopic behavior of fine particles in a packed layer, the authors developed a model of fine particle movement by DEM, which consists of the interaction between the fine material and packed material and the interaction between fine particles, as shown in Fig. 32. ${ }^{52,53)}$ Figure 33 shows the results of a calculation of a fine particle group which is being moving in the upward direction by the drag of the gas flow from the lower part. A condition can be observed in which fine particles adhere to the lower surface of the packed particles, and fine particles are dispersed upward in the interstices between those larger particles. These results are consistent with the results of a cold experiment. $^{54)}$ Figure 34 shows the stress applied to fine particles which are progressively blocking the interstices between the packed particles. ${ }^{52)}$ The mechanism of blockage can be understood from this analysis; namely, when fine particles concentrate in a narrow opening, particles from below will adhere to those particles, loading is applied between the fine particles, and eventually a bridge of fine particles forms. In the future, this method is expected to be applied to cases in which the packed layer structure is changed, and to cases in which the direction of movement of the gas flow changes from horizontal to upward at tuyeres.

\section{Future Outlook}

In the past, measured information on the blast furnace

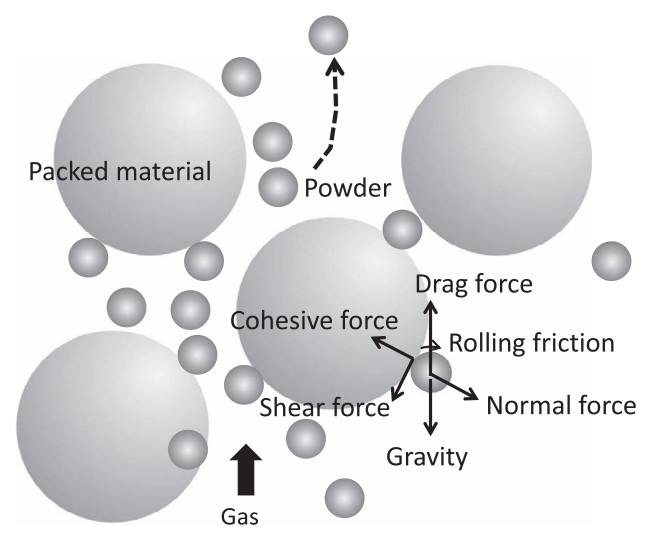

Fig. 32. Element model of powder movement by DEM. was limited, and the inner state of the blast furnace was regarded as a "black box". First, therefore, priority was placed on research on macroscopic numerical models for understanding the condition of the furnace as a whole, and those models played a role in operation design and analysis. However, considering the future needs for blast furnace models, as mentioned in the Introduction, it will be necessary to develop more advanced models which answer diverse needs, from a grasp of the furnace as a whole to analysis of local behaviors, while also providing a higher level of spatial resolution. Discrete methods are assembled from element phenomena. Therefore, unlike conventional methods, in principle, it is possible to describe a variety of phenomena in models based on information in single particle units. These include model descriptions of the burden distribution formation and descent behavior, gas flow linked to particle movement, changes in the characteristics of the cohesive zone, and the movements of the liquid phase and fine particles. The range of application of this approach is gradually expanding thanks to the progress of numerical method and computer capability. In principle, the discrete method can respond to the needs mentioned above. Utilizing the strengths of the discrete method, the properties peculiar to the blast furnace have been clarified based on information on individual particles. The image of a total model of the blast furnace based on discrete phenomena is shown in Fig. 35. Visual information and numerical information on various types of behavior in the blast furnace can now be obtained simultaneously, and it has become possible to understand the actual image of the blast furnace, which had not been visible in the past. Nevertheless, extension to the total system of the blast furnace is still a "work in progress". Models which include reactions and heat transfer still have not realized a total model that integrates the flows, reactions, heat transfer, and other phenomena at the actual blast furnace scale. Where such a total model is concerned, it would seem that continuum models are superior at the present point in time, but issues remain in their ability to deal with the complex layer structure, mixed charging, etc. From this viewpoint, high expectations are placed on discrete methods.

Table 1 shows the structure of the calculation method and the relationship between the scale of the object process and the elements included in each model. The calculation method can be divided into three types such as Eulerian method, Eulerian- Lagrangian method and Lagrangian method by the model structure. The conventional continuum model is based on the Eulerian method. The combination model of DEM with CFD as shown in Fig. 13 or Fig. 26 is a typical Eulerian-Lagrangian method. In particular, the packed bed model as shown in Fig. 26 includes chemical reaction and heat transfer. Particle method such as MPS is a representative Lagrangian method, reflecting the detailed local information on each particle and liquid droplet. Eulerian method is based on the fixed mesh; on the contrary, in Lagrangian method mesh setting is unnecessary and representation of complicated layer structure or mixed layer is possible. Accordingly, in blast furnace simulation, Lagrangian method such as the particle method has a high flexibility in spatial resolution; however, its application is currently limited to the physical phenomenon due to the computational work- 
Table 1. Characteristics of various models.

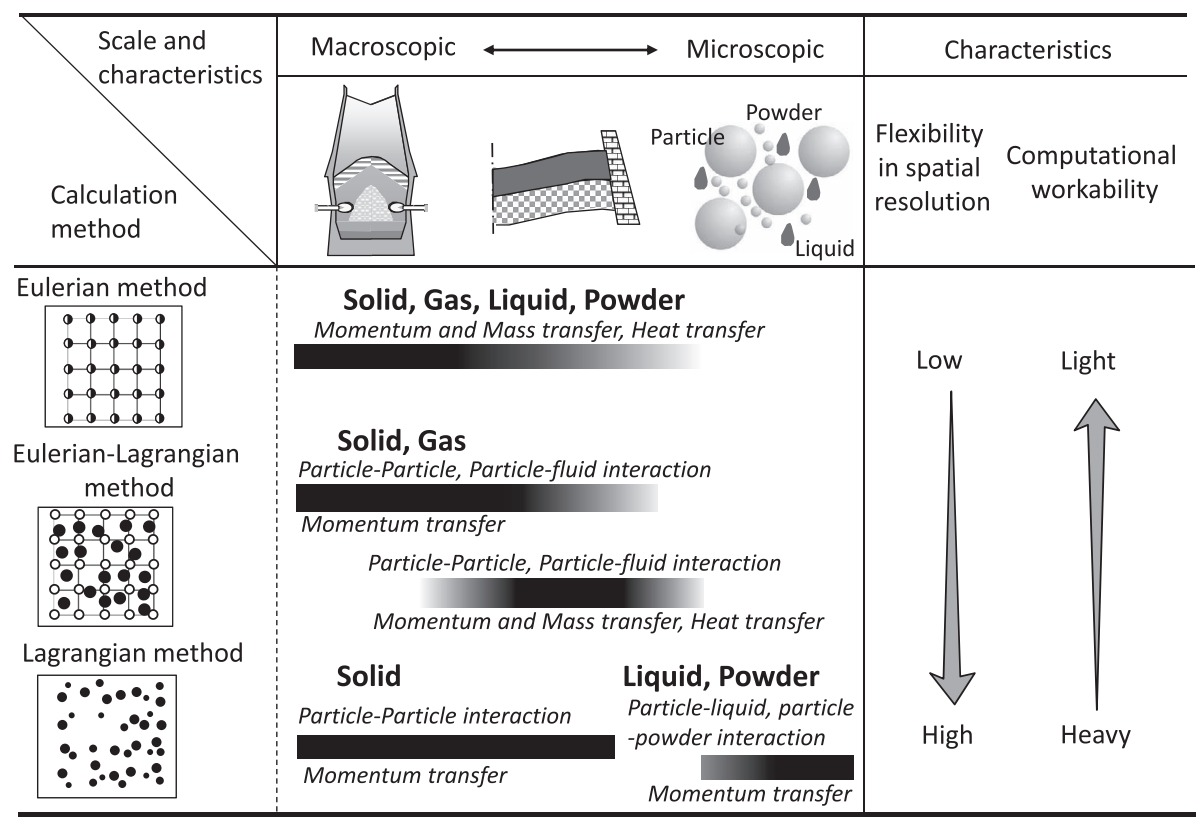

ability. All models have respective differences and distinctive features in terms of flexibility in spatial resolution and computational workability derived from the model structure. A tradeoff relationship between flexibility in spatial resolution and calculation load exists. The ultimate aim is the construction of a total model. However, joint use of these models in a hierarchical manner, considering the necessary spatial resolution and computational load conditions corresponding to the purpose of use, appears to be a realistic approach.

In recent years, steady progress has been made in computer performance. In the future, it seems that modeling of the blast furnace will gradually approach the goal of integrating the element models by further development of the Eulerian-Lagrangian method, which provides excellent resolution by retaining the feature of discontinuous particle information, while simultaneously offering the advantages of the continuum method. At the same time, not only numerical computation technology, but also ingenuity in numerical methods for describing phenomena is considered necessary, for example, in proposing rational models based on a balance of local and general information. Incorporating both of these aspects will make it possible to carry out total analyses of the blast furnace combining particle properties including reaction characteristics and the structure of the packed bed, and to perform various hypothetical experiments based on blast furnace control factors. In fact, it seems that we are not far from realization of a desktop virtual blast furnace.

\section{Conclusion}

This paper has presented an overview of recent needs in connection with blast furnace models, together with trends in the development of models which answer those needs by modeling based on the discrete method. The key points are summarized below.

Because particle motion determines the structure in the blast furnace, the modeling of particle motion is extremely important in modeling of the blast furnace. The discrete method enables precise description of the movement of particles in the blast furnace. The development of discrete models has reached a stage where it now is possible to express the movement of solids in the blast furnace as a whole. Coupling that solid movement with a gas flow model makes it possible to obtain diverse types of information, not limited to the 3-dimensional gas flow in the furnace, but also including the load on particles, the stability of burden descent. This method can also be applied to phenomena related to ore softening in the melting zone. Continuing progress is being achieved in research on discrete methods such as the particle method as new analytical methods as a result of application of such methods to analyses of the motion of droplets and motion of fine particles in the lower furnace. Finally, the features of various models were compared, and the future outlook for blast furnace modeling was discussed.

\section{REFERENCES}

1) S. Watakabe, K. Takeda, H. Nishimura, S, Goto, N. Nishimura, T. Uchida and M. Kiguchi: Tetsu-to-Hagané, 92 (2006), 901.

2) T. Yamamoto, T. Sato, H. Fujimoto, T. Anyashiki, K. Fukuda, M. Sato, K. Takeda and T.Ariyama: Tetsu-to-Hagané, 97 (2011), 501.

3) P. R. Austin, H. Nogami and J. Yagi: ISIJ Int., 37 (1997), 458.

4) P. R. Austin, H. Nogami and J. Yagi: ISIJ Int., 37 (1997), 748.

5) S. Natsui, S. Ueda, Z. Fan, N. Andersson, J. Kano, R. Inoue and T. Ariyama: ISIJ Int., 50 (2010), 207.

6) T. Kon, S. Natsui, S. Ueda, R. Inoue and T. Ariyama: ISIJ Int., 52 (2012), 1565.

7) X. Dong, A. Yu, J. Yagi and P. Zulli: ISIJ Int., 47 (2007), 1553.

8) S. Ueda, S. Natsui, H. Nogami, J. Yagi and T. Ariyama: ISIJ Int., 50 (2010), 914.

9) J. Yagi and I. Muchi: Trans. Iron Steel Inst. Jpn., 10 (1970), 392.

10) T. Sugiyama and M. Sugata: Seitetsu Kenkyu, (1987), No. 325, 34

11) K. Takatani, T. Inada and Y. Ujisawa: ISIJ Int., 39 (1999), 15.

12) P. A. Cundall and O. D. L. Strack: Geotechnique, 29 (1979), 47.

13) S. Ueda, S. Natsui, Z. Fan, H. Nogami, R. Soda, J. Kano, R. Inoue and T. Ariyama: ISIJ Int., 50 (2010), 981.

14) A. T. Adema, Y. Yang and R. Boom: ISIJ Int., 50 (2010), 954.

15) M. Akashi, H. Mio, A. Shimosaka, Y. Shirakawa, J. Hidaka and S. Nomura: ISIJ Int., 48 (2008), 1500.

16) S. Natsui, S. Ueda, Z. Fan, J. Kano, R. Inoue and T. Ariyama: Tetsuto-Hagané, 96 (2010), 1.

17) Y. Kajiwara, T. Inada and T. Tanaka: Tetsu-to-Hagané, 75 (1989), 235. 
18) T. Nouchi, T. Sato, M. Sato, K. Takeda and T. Ariyama: ISIJ Int., 45 (2005), 1426

19) C. K. Ho, S. M. Wu, H. P. Zhu, A. B. Yu and S. T. Tsai: Miner. Eng., 22 (2009), 986.

20) H. Mio, S. Komatsuki, M. Akashi, A. Shimosaka, Y. Shirakawa, J. Hidaka, M. Kadowaki, S. Matsuzaki and K. Kunitomo: ISIJ Int., 48 (2008), 1696

21) H. Mio, S. Komatsuzaki, M. Akashi, A. Shimosaka, Y. Shirakawa, J. Hidaka, M. Kadowaki, S. Matsuzaki and K. Kunitomo: ISIJ Int., 49 (2009), 479.

22) Y. Yu and H. Saxen:ISIJ Int., 52 (2012), 788

23) M. Shimizu, Y. Kimura, M. Isobe, C. Che and S. Inaba: Tetsu-toHagané, 73 (1987), 1996.

24) K. Nakano and H. Yamaoka: Tetsu-to-Hagané, 92 (2006), 939.

25) Z. Zhou, H. Zhu, A. Yu and P. Zulli: ISIJ Int., 50 (2010), 515.

26) T. Umekage, M. Kadiwaki and S. Yuu: ISIJ Int., 47 (2007), 659.

27) S. Yuu, T. Umekagae, S. Matsuzaki, M. Kadowaki and K. Kunitomo: ISIJ Int., 50 (2010), 962.

28) S. Natsui, H. Nogami, S. Ueda, J. Kano, R. Inoue and T. Ariyama: ISIJ Int., 51 (2011), 41.

29) H. Nishio and T. Ariyama: Tetsu-to-Hagané, 66 (1980), 1878.

30) S. Natsui, S. Ueda, H. Nogami, J. Kano, R. Inoue and T. Ariyama: ISIJ Int., 51 (2011), 51

31) S. Natsui, S. Ueda, H. Nogami, J. Kano. R. Inoue and T. Ariyama: ISIJ Int., 51 (2011), 1410.

32) H. Nishio and T. Miyashita: Tetsu-to-Hagané, 59 (1973), 1506.

33) H. Kurosawa, S. Matsuhashi, S. Natsui, T. Kon, S. Ueda, R. Inoue and T. Ariyama: ISIJ Int., 52 (2012), 1010.

34) H. Nishioka, S. Ujisawa and K. Takatani: CAMP-ISIJ, 25 (2012), 957.

35) S. Matsuhashi, H. Kurosawa, S. Natsui, T. Kon, S. Ueda, R. Inoue and T. Ariyama: ISIJ Int., 52 (2012), 1990.

36) S. Watakabe, T. Nouchi, T. Hirosawa and M. Sato: CAMP-ISIJ, 26
(2013), 21, CD-ROM.

37) S. Natsui, T. Kon, S. Ueda, J. Kano, R. Inoue, T. Ariyama and H. Nogami: Tetsu-to-Hagané, 98 (2012), 341.

38) S. Natsui, R. Shibasaki, T. Kon, S. Ueda, R. Inoue and T. Ariyama: ISIJ Int., 99 (2013), 1770.

39) T. Sugiyama, T. Nakagawa, H. Sibaike and Y. Oda: Tetsu-to-Hagané, 73 (1987), 2044

40) Y. Ohno and M. Schneider: Tetsu-to-Hagané, 74 (1988), 1923.

41) M. Matsuura and Y. Ohno: Tetsu-to-Hagané, 80 (1994), 884

$42)$ G. X. Wang, J. D. Litster and A. B. Yu: ISIJ Int., 40 (2000), 627.

43) M. Sasaki, K. Ono, A. Sasaki, A. Suzuki, Y. Okuno, K. Yoshizawa and T. Nakamura: Tetsu-to-Hagané, 62 (1976), 559.

44) H. Kawabata, K. Shinmyou, T. Harada and T. Usui: ISIJ Int., 45 (2005), 1474.

45) K. Nishioka, D. Fujiwara, K. Ohno, T. Maeda and M. Shmizu: ISIJ Int., 50 (2010), 1016.

46) S. Koshizuka and Y. Oka: Nucl. Sci. Eng., 123 (1996), 421.

47) M. Kondo, S. Koshizuka and M. Takimoto: Trans. JSCES, 2007 (2007), 21

48) K. Nishioka, K. Ohno, T. Maeda and M. Shimizu: Recent Progress on Mathematical Modeling in Ironmaking 2008, ISIJ, Tokyo, (2008), 65 .

49) T. Kon, S. Natsui, S. Ueda, R. Inoue and T. Ariyama: ISIJ Int., 53 (2013), 590.

50) H. Yamaoka: Tetsu-to-Hagané, 72 (1986), 2194.

51) K. Shibata, M. Shimizu, S. Inaba, R. Takahashi and J. Yagi: Tetsuto-Hagané, 77 (1991), 1267.

52) S. Natsui, S. Ueda, H. Nogami, J. Kano, R. Inoue and T. Ariyama: Chem. Eng. Sci., 71 (2012), 274.

53) S. Kikuchi, S. Natsui, T. Kon, S. Ueda, R. Inoue and T. Ariyama: CAMP-ISIJ, 26 (2013), 125.

54) T. Ariyama, M. Sato and Y. Asakawa: Kagaku Kogaku Ronbunshuu, 22 (1996), 171. 